\title{
The pricing of green bonds: external reviews and the shades of green
}

\section{Gregor Dorfleitner ${ }^{1,2}$ (]) Sebastian Utz ${ }^{3} \cdot$ Rongxin Zhang $^{1}$}

Received: 19 October 2020 / Accepted: 26 February 2021 / Published online: 1 April 2021

(C) The Author(s) 2021

\begin{abstract}
We investigate the asset pricing implications of the greenness of bonds. To estimate a green-pricing effect, we determine the 'green bond premium' as the difference between the yields of matched conventional and green-labeled bonds. On a crosssectional average, green bonds experience a statistically significant positive premium. This premium increases with external greenness evaluations, i.e., investors accept premiums of up to 5 basis points for bonds with a substantial environmental agenda. This external validation effect, which is strongest for bonds that are rated dark-green, may offset not incurring information costs, as this effect decreases with increasing age of bonds.
\end{abstract}

Keywords Green bond premium · External review $\cdot$ Second-party opinion $\cdot$ Shade of green $\cdot$ Climate finance $\cdot$ Impact investing

Jel Classification 91B76 $\cdot 91 \mathrm{~B} 16 \cdot 62 \mathrm{P} 20$

\section{Introduction}

In recent finance literature, there has been a lively debate on the asset pricing implications of sustainable and particularly green investment opportunities (Bolton and Kacperczyk 2021; Cheema-Fox et al. 2019). While existing studies focus mainly on equity, green bonds are also an important innovative financing tool for addressing environmental and climate challenges (Ehlers and Packer 2017). In the last decade, green bonds have become increasingly appealing to investors (Krueger et al. 2020). Moreover, since the European Investment Bank issued the first green bond in 2007, the

Gregor Dorfleitner

gregor.dorfleitner@ur.de

1 Department of Finance, University of Regensburg, 93040 Regensburg, Germany

2 CERMi (Centre for European Research in Microfinance), Brussels, Mons, Belgium

3 School of Finance, University of St. Gallen, 9000 St. Gallen, Switzerland 
green bond market has experienced exponential development. According to the Climate Bond Initiative (2020), the worldwide annual issue volume has grown from less than 40 billion USD in 2014 to over 160 billion USD in 2018 and 257.7 billion USD in 2019 worldwide. This rapid growth which indicates an increasing amount of funds to finance climate change adaptation and mitigation, has also attracted the attention of academics. Existing studies explore whether issuers of such green securities enjoy lower costs of financing, and at the same time, whether investors request lower returns.

In this study, we exploit the green bond market as a laboratory for testing the asset pricing implications of investment vehicles dedicated to actions related to climate change. We measure the asset pricing implications of bond greenness in terms of the so-called 'green bond premium', i.e., the difference between the yields of matched green and conventional bonds. In particular, we systematically examine the existence of the green bond premium and analyze how it is influenced by external evaluation for a bonds greenness. We extend the methodological frameworks of earlier related studies (Hachenberg and Schiereck 2018; Nanayakkara and Colombage 2019; Zerbib 2019) by a stricter matching approach, a more precise measurement of the green bond premium, and a larger sample to analyze the green bond premium as the yield difference between green bonds and synthetic conventional bonds. The latter bonds are created by matching a pair of conventional bonds to each green bond and adjusting the maturity by interpolation. Our main finding is that investors reward green bonds that are approved by external reviews, documenting the bond's serious and genuine green purposes, with a premium in the sense of lower yields and higher bond prices.

The existence of such a green bond premium is in contrast to the modern portfolio theory, which makes the assumptions of rational investors, efficient markets, and expected returns as a function of risk. Nevertheless, asset pricing literature has shown that, additionally to these assumptions, several anomalies predict asset prices (Harvey et al. 2016). More specifically, behavioral finance literature generally assumes that investors are imperfect and subject to many emotional biases, i.e., behavioral finance differs from traditional finance in that it focuses on how investors actually behave, rather than theorizing how they should behave. In our particular case, green bonds cater for both the traditional financial and green objectives of bond investors. Therefore, green impact investors may achieve utility from the green investment outcome besides the utility gained from financial performance. Thus, following this utility paradigm, which goes one step beyond the irrationality-based behavioral finance perspective, green bonds could be priced higher than comparable conventional bonds, as the non-financial utility component may compensate for a lower financial return for green impact investors. To identify whether this pattern applies on financial markets and how the level of greenness impacts the green bond premium, is the research gap that needs to be filled. Some evidence on whether such a premium really prevails amongst investors exists (e.g., Baker et al. 2019; Bachelet et al. 2019; Zerbib 2019), but no consensus has been reached, and the findings so far paint an unclear picture. While there is some evidence supporting a positive green bond premium and the appreciation of the greenness of these instruments (Baker et al. 2019), other studies elicit no green bond premium or even a negative one (Bachelet et al. 2019; Climate Bond Initiative 2019b). 
Our paper develops a theoretical framework for a 'greenness bias' in expectations of green bond investors and conducts empirical tests based on a sample of 250 matched bond triplets in the period from 2011 to 2020 containing more than 90,000 daily observations. To determine the matched bond triplets we applied a rigorous matching process. Moreover, we build a comprehensive dataset by consolidating various sources of information on green bonds and their comparable counterparts. To investigate the pricing mechanism of green bonds, we run hybrid regressions and focus on different types of external review reports and their evaluation results, to explain the variations in the distribution of green bond premiums. Furthermore, we control liquidity difference via a hybrid model, in order to extract the real green bond premium.

Our results show that, on average, green bonds enjoy an expected positive premium (approximately $1 \mathrm{BP}$ ) over comparable conventional bonds. Indeed, some green bonds do have an evidently higher premium than others. Reports from independent external reviewers are a main driver for investors to pay a significant green bond premium. However, the type of external review is crucial. While there is no evidence that external reviews such as a certification assigned by the Climate Bond Initiative (CBI) and a green rating from traditional credit rating agencies have a positive influence on the green bond premium, green bonds with a second-party opinion and a verification enjoy significantly lower yields, i.e., are traded at a positive premium (3-4 BP). Particularly second-party opinions asserting a 'dark green' or 'medium green' shade tend to be associated with a positive premium (5 or $4 \mathrm{BP}$, respectively). This finding adds to the discussion of whether investors are willing to pay more for certified green and sustainable investments (see e.g., Gutsche and Ziegler 2019).

This finding also adds to the debate on whether green bonds could be used for financing regular non-green projects (Flammer 2020) and as a tool for green-washing (Walker and Wan 2012; Nyilasy et al. 2014). If this were the case, the green bond market would lose much of its credibility, and investors might start to ignore the green label. Therefore, preserving the integrity and credibility of green bonds is at the core of building a healthy green bond market. To mitigate the risk of greenwashing, the International Capital Market Association (ICMA) recommends issuers to appoint an independent external reviewer to confirm the alignment of their green bonds with the 'Green Bond Principles' (GBPs). Consequently, external reviews are the main approach to enhancing the integrity and credibility of the green bond market (Shishlov et al. 2016). With a growing market, the role of independent external reviewers is becoming even more prominent. However, to the best of our knowledge, very few studies present empirical indications that external reviews impact investor decisions and thereby the pricing of green bonds (Baker et al. 2019; Bachelet et al. 2019; Larcker and Watts 2020). The question of whether different types of external reviews create value for investors has not yet been answered. Moreover, even though an increasing number of external reviewers explicitly evaluate detailed greenness issues instead of a general assessment, it is unanswered how investors react to the external greenness assessments.

Our empirical results provide evidence that investors rely on external reviews, especially second-party opinions and verifications, as a source of proven information 
on the greenness of green bonds. In particular, investors reward the integrity (expressed by second-party opinions) of green bond issuers with lower expected returns. We document that the effect of external validation on the green bond premium is strongest for bonds that are rated dark-green in second-party opinions, which affirms investors' positive perception of the shade of greenness of the project. This pattern may offset not incurring information costs, as the external validation effect decreases with increasing age of bonds. Thus, a second-party opinion, especially one with a clear evaluation conclusion in terms of a shade of green, can be one channel for investors to reduce information search costs aimed at confirming the greenness of a bond, reduces the uncertainty that the respective bond is reliably and consistently green, and thus motivates investors to buy the bond at higher prices, i.e., lower expected returns. This major finding is in accordance with the recent finding that retail investors, especially socially responsible investors, have significant preferences for socially responsible equity funds with certification and transparency logos (Gutsche and Zwergel 2020).

With these findings, our study makes the following two contributions. First, our study considers almost all green bonds which provides adequate information for our analysis and covers most of their yield development between 2011 and 2020. In contrast to earlier studies that focus on a specific time frame or a relatively small sample (e.g., Ehlers and Packer 2017; Nanayakkara and Colombage 2019), our setting for analyzing the green bond premium is comprehensive and minimizes potential bias that could influence the statistical estimations. Furthermore, our stringent matching process ensures that the observed yield premium between green and corresponding conventional bonds can be regarded as the 'real' green bond premium. Second, this is the first study to systematically examine the impact of all four different kinds of external review reports on the pricing of green bonds. ${ }^{1}$ To this end, we collect all available external review reports from major green bond databases or official issuer websites and classify them into different categories based on their formats and evaluation results. This dataset enables us to determine that serious climate action confirmed by 'dark green' and 'medium green' second-party opinions have a significant impact on the green bond premium. Nevertheless, the value of confirming climateprotection-related issues for investors declines with the age of the green bond. In terms of practical and policy implications, the reliability of external reviews in the green bond market is important to investors, and thus has implications for the cost of capital for financing climate-change adaption and mitigation.

The remainder of the paper is organized as follows. In Sect. 2, we discuss the importance of green credentials and the role of external review reports in the green bond market. We review the literature on the green bond premium and develop several hypotheses in Sect. 3. Section 4 presents our sample and Sect. 5

\footnotetext{
${ }^{1}$ Several studies also touch upon this question (Baker et al. 2019; Bachelet et al. 2019; Larcker and Watts 2020), but only to a minimal extent. For instance, Bachelet et al. (2019) adopt subsample analysis to examine the role of 'third-party verification', while Baker et al. (2019) include only a dummy variable to investigate the general influence of the CBI certification. None of these studies treats different types of external reviews separately, or examine the evaluated greenness (shade of green).
} 
the methodological approach. Section 6 contains the empirical results and Sect. 7 concludes.

\section{The green bond market: institutional details}

\subsection{Green bond labels}

The development of the green bond market in the past decade demonstrates the huge demand for climate adaptation and mitigation investments. Indeed, studies show that both institutional and retail investors with a focus on sustainable investment have a strong interest in investing in green bonds (Climate Bond Initiative 2019a, b). Also, from an issuer perspective, green bonds can provide an ideal financing source for green projects. Besides fulfilling their commitment to the environment, green bond issuers may enjoy lower costs of capital in the primary market (Ehlers and Packer 2017).

Originally, the proceeds from green bonds were intended to be used for green projects such as renewable energy or energy efficiency projects. As more and more issuers from various sectors entered the market, the concern arose that green bonds could be misused to finance greenwashing projects (Flammer 2020). Shishlov et al. (2016) point out that one of the two major challenges for the green bond market is to ensure its environmental integrity so as to mitigate the green-washing criticism that could threaten its survival. Investors are also aware of the greenwashing risk. According to an investor survey conducted by CBI (Climate Bond Initiative 2019a), green credentials and issuer transparency are the most important factors for green bond investors making investment decisions.

However, the green bond market is generally not subject to government regulation and there are only a few voluntary rules to prevent the possibility of greenwashing. Currently, the voluntary process guidelines proposed by ICMA, called 'Green Bond Principles' (GBPs), are regarded as the most widely accepted standards to promote the integrity of the green bond market. To ensure that green bonds make the expected contribution to the environment, issuers can disclose an overall green bond framework which has four core components, comprising (1) the use of proceeds, (2) process for project evaluation and selection, (3) managing of the proceeds, and (4) reporting, as defined by the GBPs. Yet, the fact that issuers can label their bonds as green and draft a green bond framework on their own, results in a need to seek independent and professional external reviewers to examine the alignment with the GBPs and the greenness of the bonds. Therefore, the GBPs encourage green bond issuers to seek external reviews, besides releasing statements on the four core components.

\subsection{Different external green bond reviewers}

According to the GBPs, there are generally four types of external review report, namely second-party opinion, verification, certification, and green rating. Each 
green bond can have just one or several types of external review. External reviewers are usually independent research institutions dedicated to environmental research such as the Center for International Climate Research (CICERO) and ISS-Oekom. They examine the alignment of green bonds with the GBPs, or evaluate greenness based on their specific criteria and methodologies. These external reviewers are intended to facilitate communication between investors and issuers, and thus contribute to a healthy and prosperous green bond market.

Second-party opinions (SPOs) are the most popular external reviews for green bonds. Each green bond can have an SPO issued by an independent research institution such as CICERO, ISS-Oekom, and Sustainalytics. SPOs are usually detailed and comprehensive, providing a thorough analysis of the four core components of the GBPs and other related issues. An SPO released by CICERO mainly contains a description and an assessment of the issuer's green bond framework, rules, and procedures for climate-related activities. The assessment part of the report comprises strengths, weaknesses, and pitfalls of the green bond framework. Moreover, some SPOs even provide a broad qualitative indication of the true greenness of green bonds. For instance, CICERO's SPOs are graded into several shades, namely 'dark green', 'medium green', 'light green', and 'brown', indicating the possible environmental impact of the green bond and the robustness of the issuer's governance structure that supports the framework. According to CICERO's criteria, ${ }^{2}$ 'dark green' is only awarded to green projects and solutions that represent the best way to realize the long-term vision of a climate-resilient future. For instance, the 2015 green bond framework of the German state-owned development bank KfW obtained such a 'dark green' shade from CICERO, because of its clear and exclusive focus on renewable energy and robust procedures for project screening. However, in 2019 the KfW green bond framework received the 'medium green' shade from CICERO. Even though the proceeds are allocated to provide favorable loans for renewable projects and the construction of energy efficiency buildings to push forward the usage of fossil-free sources, the 2019 green bond framework cannot fully guarantee the exclusion of fossil fuels (see CICERO 2019) and thus regarded as somewhat less green as the 2015 one. ${ }^{3}$ Moreover, 'light green'-shaded bonds finance mere quickfix solutions that help initiate the transition towards the long-term vision, such as improvement of energy efficiency in fossil-based activities. The so-called 'brown' shade (which does not occur for any bond in our sample) indicates a bond's negative ecological impact. Besides CICERO, other SPO providers have a similar evaluation methodology in their SPO reports (see Table 1). For comparison purposes among different greenness evaluations, we convert the different schemes of greenness evaluation into one scale represented by the shades of 'dark green', 'medium green', 'brown', and 'no shade'. A green bond is awarded with the shade of dark green if it exhibits an above-average positive evaluation, while the shade of medium green indicates a level of greenness that SPO provider considers to be standard in the green bond market. Bonds classified as brown shade show below-average or

\footnotetext{
2 The CICERO's shade of methodology: https://www.cicero.green.

${ }^{3}$ See also CICERO (2015). We compare those two SPOs and come to this conclusion.
} 
Table 1 Different shade of green schemes

\begin{tabular}{|c|c|c|c|c|}
\hline Shade & CICERO & Vigeo & ISS-Oekom & Sustainalytics \\
\hline Dark green & Dark green & Reasonable & $\begin{array}{l}\text { Excellent } \\
\text { Good }\end{array}$ & $\begin{array}{l}\text { Leader } \\
\text { Outperformer }\end{array}$ \\
\hline Medium green & $\begin{array}{l}\text { Medium green } \\
\text { Light green }\end{array}$ & Moderate & Medium & Average performer \\
\hline Brown & Brown & Weak & Poor & $\begin{array}{l}\text { Underperformer } \\
\text { Laggard }\end{array}$ \\
\hline No shade & No clear shade & No clear shade & No clear shade & No clear shade \\
\hline
\end{tabular}

negative evaluation results. When no specific shade of green is explicitly expressed in an SPO, it is classified as having no shade in this study. In that case, green bond investors must be able to draw on their own overall judgment, based on positive and negative signals implicitly delivered by SPO providers.

Verification reports are, compared with SPOs, generally less lengthy and detailed, ${ }^{4}$ and issued by auditing companies such as $K P M G$ and $P w C$. In verification reports, reviewers accomplish predefined tasks such as examining whether the use of proceeds is aligned with the GBPs or other related national regulatory rules. Finally, they provide a statement on the question of whether the issuer has violated any requirements defined by the GBPs or by the issuer (on voluntary basis). Therefore, it can be stated that verification reviewers evaluate green bonds more objectively, while SPO reviewers deliver subjective and comprehensive opinions on green bonds, according to their own standards.

CBI certification is another type of external reviews. CBI as a well-known international organization dedicated to the development of the green bond market, offers a certification scheme which is based on scientific criteria ensuring consistency with the 2 degree Celsius warming of the Paris Agreement. CBI can award green bonds a certification through the approved verifiers. ${ }^{5}$ When assigned a CBI certification, a green bond obtains the recognition of $\mathrm{CBI}$ regarding its greenness.

Green rating reports are issued by traditional credit rating agencies such as Moody's and S\&P. For instance, Moody's assigns five grades of green ratings to green bonds, ranging from 'excellent' to 'poor'. At first glance, green ratings are similar to SPOs with a shade of green, since they both provide a greenness assessment. However, green rating reports from credit rating agencies are regarded as a different type of external review, as they are more quantitative and focus on issuers' environmental performance data. Moreover, they are far less frequent than SPO reports in the green bond market.

\footnotetext{
4 A verification report normally has only 2-3 pages.

5 A complete list of approved verifiers can be seen on the official website of CBI.
} 


\section{Literature review and hypotheses development}

\subsection{The green bond premium and its determinants}

Several studies analyze the green bond premium and its determinants. Regarding the question of whether green bonds enjoy a significant premium, earlier studies show mixed empirical evidence. While some studies find evidence that green bonds enjoy a positive premium (e.g., Baker et al. 2019: 6 BP; Nanayakkara and Colombage 2019: 63 BP; Zerbib 2019: 2 BP), other studies cannot confirm its existence (Climate Bond Initiative 2019b; Larcker and Watts 2020; Flammer 2020). Bachelet et al. (2019) even find that green bonds are slightly underpriced and thus have a negative premium $(-2 \mathrm{BP})$. Differences in the identification strategy, sample selection, and observation period potentially cause diversity in the results (see the overview on the methodological spectrum of studies in Table 1 of Zerbib 2019). Concerning the identification strategy, a comparison of the yield from green and conventional bonds could be conducted in the primary market (Ehlers and Packer 2017; Climate Bond Initiative 2019b) or on the secondary market by indirectly examining the impact of the green label by regressing the bond yield on a green label indicator (e.g., Baker et al. 2019; Nanayakkara and Colombage 2019). Some recent studies extract the green bond premium by adopting a matching approach (Hachenberg and Schiereck 2018; Bachelet et al. 2019; Zerbib 2019), which enables researchers more precisely to estimate the premium.

Besides the inconsistent findings on the existence of a green bond premium, a few approaches analyze possible green bond determinants. Hachenberg and Schiereck (2018) and Zerbib (2019) show that basic bond features such as the credit rating and issuer type influence the green bond premium. Also, liquidity is confirmed as a major determinant of yield spreads of green bonds (Wulandari et al. 2018; Zerbib 2019). Moreover, some preliminary findings show that green credentials are important for the cost of green bonds (Baker et al. 2019; Bachelet et al. 2019; Li et al. 2019). In particular, Baker et al. (2019) investigate the pricing of 2083 U.S. municipal and 19 corporate green bonds and find that green bonds with a CBI certification have yields 26 BP lower than ordinary bonds with similar characteristic. Bachelet et al. (2019) focus on 89 matched green bonds and find that those green bonds issued by private firms with external reviews show a small premium (1 BP). Kapraun and Scheins (2019) analyze 641 green bonds and observe that certified green bonds have yields 2 BP lower than green bonds without a certification and green bonds traded on green exchanges show lower yields (7 BP) because they are required to meet some standards set by green exchanges. In contrast, Larcker and Watts (2020) examine a matched sample of 640 municipal green bonds and find that the CBI certification make no significant difference in the pricing of municipal green bonds.

Nevertheless, these earlier studies have several drawbacks. For instance, some of them do not apply a strict matching process (see e.g., Baker et al. 2019; Kapraun and Scheins 2019) to gain more observations and thus may be subjected to estimation biases. Some of them focus only on a sub-sector of the green bond 
market such as the U.S. municipal bonds (see e.g., Baker et al. 2019; Larcker and Watts 2020). Most importantly, neither of these studies investigates the impact of the four different categories of external reviews that we have separately discussed above (earlier related studies mostly focus on the CBI certification, see e.g., Baker et al. 2019; Larcker and Watts 2020). Moreover, these studies ignore the impact of specific evaluations of greenness levels in external reviews, i.e., the shade of green methodology in SPOs, on the green bond premium, despite their existence and increasing popularity in recent years.

\subsection{Hypotheses development}

A green bond premium, defined as the difference between the yield of a green bond and a comparable conventional bond may be due to the price impact of investor preferences regarding the climate-change exposure of assets (Painter 2020). For instance, Gutsche et al. (2019) find that there is a significant positive correlation between socially responsible investments and the dummy variable for retail investors' environmental values (i.e., whether a respondent is a member of an environmental organization) based on a representative survey. As Fama and French (2007) put it, the demand for green assets is an investors' taste that adjusts equilibrium prices.

Our theoretical framework relies on the investors' taste argument, i.e., investors appreciate non-financial aspects of an investment. ${ }^{6}$ In this regard, some investors are willing to sacrifice a certain proportion of the return in order to achieve a nonfinancial utility from the investment (Dorfleitner and Utz 2014; Riedl and Smeets 2017). ${ }^{7}$ Moreover, Höchstädter and Scheck (2015) reveal that impact investors aiming at environmental (or social) impact accept some curtailment of the achievable financial return.

We measure the bond performance through the yield $r_{B}$ of a bond $B$. In a setting with combined financial and non-financial investor preferences (see Dorfleitner and Utz 2012), investors assess a bond $B$ with the functional

$$
r_{B}+\alpha g_{B},
$$

where the parameter $\alpha$ represents preferences for the (expected) greenness $g_{B}$ of the bond with a yield $r_{B}$. Accordingly, we derive an equation describing an investor's preferences regarding a green bond (GB) and a comparable conventional bond (CB). If a green bond has a yield $r_{G B}$ and an expected greenness $g_{G B}$, while the

\footnotetext{
${ }^{6}$ Note that there is mixed evidence on whether sustainable and especially environmental-friendly (stock) investments yield a financial under- or out-performance (Orlitzky et al. 2003). However, this question is not relevant in our context, as the green bond premium corresponds by definition to a lower return, compared to a comparable conventional investment.

7 One might see this phenomenon as the flip side of the well-known sin-stock effect, according to which stocks of especially unethical firms yield a higher return than otherwise comparable stocks because of investor preferences (Hong and Kacperczyk 2009).
} 
conventional bond has a yield $r_{C B}$ and no greenness, then an $\alpha^{*}$ exists such that at a given point in time

$$
r_{G B}+\alpha^{*} g_{G B}=r_{C B}
$$

Different investors may-depending on their non-financial preferences-yield different values for $\alpha \geq 0$ (Berry and Yeung 2013). If specific investors have a higher appreciation of greenness than the market-related $\alpha^{*}$, they will have a preference for the green bond. Therefore, they are willing to buy the bond at the current yield level. Aggregated over all investors, this effect yields a positive value of $\alpha^{*}$ and thus explains a positive green bond premium

$$
r_{C B}-r_{G B}=\alpha^{*} g_{G B}
$$

if there is a sufficiently large share of investors with positive values for $\alpha$. An $\alpha^{*}$ different from zero in this framework indicates the existence of a price impact of bond greenness.

Based on these theoretical considerations, we deduce the following hypotheses on the link between investor preferences and the green bond premium. Since the greenness of a bond is a natural component of investor decision-making, investors have a need to objectify this type of non-financial information. On a company level, ESG issues are disclosed in the non-financial reporting, which signals a company's commitment to increasing transparency, and causes a reduction of information asymmetry (Dhaliwal et al. 2012). Existing evidence suggests a negative relationship between environmental performance and cost of capital (Heinkel et al. 2001; Ghoul et al. 2011; Chava 2014).

On the green bond market, a majority of bond issuers report on the use of proceeds, typically by releasing their green bond framework or social impact reports based on the GBPs. Non-financial disclosure reduces information asymmetry regarding the implemented sustainability practices (Hahn and Kühnen 2013). Given that non-financial disclosure on environmental activities increases the green bond transparency, thus reducing uncertainty and idiosyncratic risk, investors may accept lower risk compensation, leading to a reduction in the cost of debt of green bonds. Thus, if the label 'green bond' substantially increases the transparency of green bonds for a sufficiently large proportion of green investors who imply a positive greenness $g_{G B}$ from the voluntary disclosure of the green bond issuer, then a positive $\alpha^{*}$ and thus also a positive premium $r_{C B}-r_{G B}$ can emerge.

H1: Green bonds are priced at a premium in the secondary market, compared to conventional bonds with similar characteristics.

We continue with disentangling the 'substantial increase' in green bond transparency from the 'sufficiently large' proportion of green investors by focusing on different levels of non-financial disclosure on green bonds. While we are capable of analyzing different levels of non-financial green bond disclosure as a measure of transparency, the 'sufficiently large' proportion of green investors is an implicit measure in our approach. 
A majority of green bond issuers release non-financial disclosures to increase green bond transparency, and thereby reduce information asymmetry. Nevertheless, some information asymmetry remains regarding its validity. The validity of the released information is crucial in the following considerations, since it is difficult to obtain credible factual information on the use of green bond proceeds. Voluntary non-financial disclosure could even be misused for greenwashing purposes. It is well-known that credit ratings from external rating providers can overcome information asymmetry issues to some extent (Tang 2009). Analogously, intermediaries such as external reviewers (e.g., SPO issuers and verification providers) and certification bodies can play an important role in mitigating information asymmetries regarding the non-financial aspects. From an investor perspective, external reviews thus can make green bond investments more reliable and instil more confidence (Climate Bond Initiative 2019a).

Reverting to our model, we consider the investors' possibility to obtain a stronger differentiation between bonds. To keep things simple, let us assume that the greenness can be either $G>0$ or zero. Due to information asymmetry, investors calculate the expected greenness according to

$$
g_{G B}=p \cdot G+(1-p) \cdot 0=G \cdot p
$$

with $p$ denoting the probability of the greenness being $G$ and reflecting their uncertainty in objectifying the real facts. Consider two bonds for clarification, the first (GB1) having an external review regarding its greenness, while the second (GB2) has no such confirmation. It is plausible that such an external review would in most cases increase the probability of $p$, namely in those cases in which the review comes to a positive conclusion and investors trust the assessment of the external reviewer more than their own assessment of the voluntary disclosure. ${ }^{8}$ The expected greenness of the first bond is then higher $\left(g_{G B 1}>g_{G B 2}\right)$. Thus, for an investor with a fixed value of $\alpha$, a higher accepted premium $\alpha g_{G B}$ is implied.

This argumentation is in line with informational transaction cost theory. Without a review, investors who are potentially interested in a specific bond have to invest some information costs to verify whether or not the greenness is really there. If an external review is available, these research-related costs can be avoided. Such information costs are generally priced in bond markets (Fenn 2000). In our case, investors will subtract the necessary transaction costs from the decision functional $r_{G B}+\alpha g_{G B}$ when considering their effective net value, and thus demand a higher yield for GB2 than for GB1. This directly implies a lower green bond premium for GB2. Either way of argumentation leads to the second hypothesis.

H2: Green bonds with a statement from an external reviewer on their true greenness enjoy a higher green bond premium in the secondary market.

\footnotetext{
${ }^{8}$ Indeed, in our sample employed in the empirical part, there are no bonds with external reviews claiming that the corresponding issuer is prone to greenwashing. However, theoretically, this is possible and would lead to a lower probability $p$.
} 
The informational transaction cost argument implies another hypothesis. If a certain green bond without an external review has been traded on the market for some time, more and more potentially interested investors may already have spent their research-related transaction costs, which are inherently fixed costs. Therefore, following this reasoning, one can expect to observe an increasing green bond premium for those green bonds that do not have an external review, as these costs only accrue at each investor's first dealing with the specific bond. We subsume this consideration into another hypothesis.

H3: The premium of green bonds without a statement from an external reviewer on their true greenness is positively related to the duration for which the green bond has been traded on the secondary market.

Finally, we restrict our considerations to green bonds with external reviews, i.e., bonds having the same (high) value of $p$. However, different levels of greenness exist (see Table 1). Therefore, we substitute $G$ in Eq. (4) with one of the values $G_{1}$, $G_{2}$, and $G_{3}$ (with $G_{1}>G_{2}>G_{3}$ ). If one green bond (GB1) has a darker shade of green, say $G_{1}$, than another (GB2), say $G_{2}$, then $g_{G B 1}>g_{G B 2}$ for equal values of $p$. Accordingly, a specific investor with a fixed $\alpha$ would, therefore, be willing to accept a higher premium for GB1 than for GB2. This discussion leads us directly to the fourth hypothesis.

H4: Green bonds with a higher level of greenness confirmed by external parties enjoy a higher premium in the secondary market.

\section{Data description}

\subsection{The green bond dataset}

Our main green bond database is Environmental Finance (EF), which lists selflabeled green bonds and contains information on bond issuance and related documents such as external review reports. We extract, from the EF database, a complete list of straight green bonds ${ }^{9}$ issued since the inception of the green bond market in 2007 until April 2020. Moreover, we supplement the EF green bond dataset with those straight bonds marked as green bonds on Thomson Reuters Eikon. In particular, we collect any external review reports and ICMA green bond templates ${ }^{10}$ from the EF database. However, even though EF provides a comprehensive record

\footnotetext{
9 We do not consider green bonds with embedded options, since different types of options have a different impact on bond pricing, and thus disable the comparison that is necessary in the matching process.

10 To promote the transparency of the green bond market, ICMA designs a template on which issuers can publish information about their issuance of green bonds and the corresponding external reviews. Some issuers may voluntarily upload the template on ICMA's official website.
} 
of documents regarding external review reports, some data on external review is still missing. Therefore, we also download green bond datasets maintained by ICMA and CBI, both of which contain valuable information on external review reports. ${ }^{11}$ Moreover, since none of the existing data sources provides a complete record of all types of external review reports, we manually check each issuer's official website to further validate or supplement the existing information on external reviews. Furthermore, we augment the green bond database with basic bond features such as structure, seniority, and credit rating, from Thomson Reuters Eikon. In the end, we build a dataset of 1248 straight green bonds with adequate data for further analysis.

\subsection{Matching conventional and green bonds}

To isolate the impact of the green label on the bond yield, i.e., the green bond premium, the ideal setting would comprise one bond that exists in both treatments, i.e., as a green bond and a conventional bond at the same time. Since this situation could not be observed from market data, we match treated (i.e., green) bonds to otherwise comparable conventional bonds (see e.g., Bachelet et al. 2019; Zerbib 2019). Therefore, we identify, for each green bond, a list of conventional bonds with similar bond characteristics. Conventional counterfactual bonds resemble green bonds in all matching criteria, and therefore, we expect them to develop similarly to green bonds.

In general, a perfect match between green bonds and conventional bonds is unlikely, since only few parties issue such a bond pair. Therefore, we capture the remaining differences by further controls. Although a perfect matching is impossible, a rigorous matching-pair approach can derive a more reliable estimation of the green bond premium and would strip out any significant differences between green bonds and conventional bonds, other than that of the green label itself (Zerbib 2019).

Our matching approach proceeds as follows (see Fig. 2 in the Appendix). We make use of the Eikon security screener, and extract, for each green bond, all straight conventional bonds of the respective issuer. For instance, we select the matching partner of a green bond issued by Berlin Hyp AG from a pool of more than 1,000 conventional bonds also issued by Berlin Hyp AG. We consider active and inactive, i.e., expired, plain vanilla bonds. Further, we apply the matching criteria of Zerbib (2019) for comparison reasons. For potential matching partners, we require conventional bonds to have the same currency denomination, coupon type, seniority and collateral status, and credit rating ${ }^{12}$ as the green bond. Moreover, we select the issue amount of conventional bond candidates to be less than 4 times and higher than $1 / 4$ of the issue amount of the green bond, so as to account for volume difference. Additionally, we exclude those conventional bonds with an issue date six years earlier or

\footnotetext{
11 The green bond dataset from ICMA: https://www.icmagroup.org/green-social-and-sustainabilitybonds/green-social-and-sustainability-bonds-database. The green bond dataset of CBI: https://www. climatebonds.net/cbi/pub/data/bonds.

12 Note that different credit rating regimes have been integrated into the same scale as that of S\&P on Eikon.
} 
later than that of the green bond. ${ }^{13}$ By considering every possible conventional bond in the matching approach, our matching can identify the globally optimal matching result.

One major issue in the matching of green and conventional bonds is the difference that may result from different maturities of the matching partners. Since not many issuers issue green bonds and similar conventional bonds with the same maturity date, we first choose conventional bonds with a close maturity date, i.e., a maturity date that differs less than two years from that of the green bond (see Zerbib 2019). Moreover, we split the set of eligible conventional bond candidates $(C=I \cup J$, with $I \cap J=\emptyset$ ) into two groups: one including conventional bonds with an earlier maturity date (group $c b_{i}$ with $i \in I$ ) and the other of conventional bonds with a maturity date later than that of the green bond (group $c b_{j}$ with $j \in J$ ). A potential bond triplet consists of the considered green bond $(g b)$, and one bond from each of the two groups $\left(c b_{i}, c b_{j}\right)$. Therefore, the number of potential bond triplets for a green bond is the product of the numbers of conventional bonds in these two groups $(|I| \times|J|)$.

In the next step, we consider the following two aspects in order to identify the best matched triplet from all potential bond triplets. First, we take the quality and availability of yield data into account. To this end, we download daily bid and ask yield data for bonds in each potential bond triplet from Bloomberg from respective issue dates to June 2020. We drop observations with the same bid and ask yield as the previous or next trading day, or with a bid-ask spread larger than $50 \mathrm{BP}$, because constant yields or large spreads indicate bond illiquidity and the bid and ask yield data may not reflect the market conditions in these cases. Thereafter, we merge the yield data of three bonds, based on the timestamp, and exclude bond triplets that provide less than 50 joint daily observations.

Second, we account for the remaining difference in maturity by applying the following correction for each potential bond triplet $\left(g b, c b_{i}, c b_{j}\right)$. We construct all possible synthetic bonds $\left(c b_{i j}\right)$ by linear interpolation. Each synthetic bond has exactly the same maturity as the green bond, and we choose this respective synthetic bond as the final counterfactual of the green bond. Unlike some studies allowing both interpolation and extrapolation (Bachelet et al. 2019; Zerbib 2019), for consistency reasons, we implement only interpolation. ${ }^{14}$ Accordingly, the yield of the synthetic conventional bond can be calculated through

$$
r_{c b_{i j}}=r_{c b_{i}}+\frac{r_{c b_{j}}-r_{c b_{i}}}{D_{c b_{j}}-D_{c b_{i}}} \cdot\left(D_{g b}-D_{c b_{i}}\right)
$$

where $D_{c b_{i}}<D_{g b}<D_{c b_{j}}$ and $D$ represents maturity. Thus, the yield difference between the green bond and its comparable synthetic bond can be calculated:

$$
\Delta r=r_{c b_{i j}}-r_{g b}
$$

\footnotetext{
13 All the above mentioned matching criteria are exactly the same as those in Zerbib (2019).

14 Linear interpolation and extrapolation tend to have different impacts on the yield estimation and additional noises might be introduced if both of them are allowed. This is actually a stricter requirement, as it makes the search for comparable conventional bonds more difficult.
} 
We remove all observations with an absolute yield difference $|\Delta r|$ larger than 100 $\mathrm{BP}$ as a signal for data irregularities. ${ }^{15}$ To minimize the error resulting from linear interpolation, we solve the problem

$$
\begin{aligned}
& \min _{i, j}\left|D_{c b_{i}}-D_{g b}\right|+\left|D_{c b_{j}}-D_{g b}\right| \\
& \text { s.t. } i \in I \text { and } j \in J
\end{aligned}
$$

to determine the triplet with the smallest sum of absolute maturity differences as the final matched triplet $\left(g b, c b_{i^{*}}, c b_{j^{*}}\right)$.

\subsection{Liquidity adjustment}

One important determinant of the bond pricing is liquidity (Amihud and Mendelson 1986; Chen et al. 2007). Therefore, we apply the following approach to capture a possible liquidity difference in the yield difference $\Delta r$ for each potential bond triplet and to provide an accurate estimation of the green bond premium. We choose the daily bid-ask spread as the measure of liquidity in bond markets (see e.g., Schestag et al. 2016). For a single bond, we calculate the bid-ask spread $L$ as the difference between the bid and the ask yield:

$$
L=r_{\text {bid }}-r_{a s k}
$$

For the synthetic bonds, we interpolate the liquidity measure based on the liquidity of the two comparable conventional bonds:

$$
L_{c b}=L_{c b_{i^{*}}}+\frac{L_{c b_{j^{*}}}-L_{c b_{i^{*}}}}{D_{c b_{j^{*}}}-D_{c b_{i^{*}}}} \cdot\left(D_{g b}-D_{c b_{i^{*}}}\right) .
$$

Thereafter, the corresponding liquidity difference $\Delta L$ between green bonds and synthetic conventional bonds is

$$
\Delta L=L_{c b}-L_{g b}
$$

We use the liquidity difference $\Delta L$ to capture the influence of distinct liquidity on the yield difference between green and conventional bonds in the following.

\subsection{Sample and descriptive statistics}

After the matching process, we identify 250 best matched bond triplets (250 green bonds matched with 500 conventional bonds). ${ }^{16}$ We document the reduction in

\footnotetext{
15 This data cleaning procedure leads to a reduction of only 112 daily observations. We also remove this procedure or change the $100 \mathrm{BP}$ yield difference requirement to $150 \mathrm{BP}$ to see whether it may lead to biases. These additional checks show similar empirical results as the main results reported in this paper.

${ }^{16}$ Our green bonds are at least representative for plain vanilla green bonds for which a GBP can be identified. Tables 13 and 14 contain the respective summary statistics on the sample of all 1248 plain vanilla green bonds.
} 
Table 2 Descriptive statistics for metric variables

\begin{tabular}{lllllll}
\hline Variable & Obs. & Mean & Std. & Min & Median & Max \\
\hline $\begin{array}{llllll}\text { Panel: time-variant } \\
\Delta r(\%)\end{array}$ & 92,774 & -0.0012 & 0.1208 & -0.9969 & 0.0012 & 0.9834 \\
$\Delta L(\%)$ & 92,774 & -0.0019 & 0.0460 & -0.4477 & 0.0001 & 0.3898 \\
gb_yield (\%) & 92,774 & 1.6214 & 2.1388 & -0.9720 & 0.9430 & 23.0020 \\
maturity (in years) & 92,774 & 4.2459 & 3.0428 & 0.0548 & 3.5863 & 28.8110 \\
$\begin{array}{l}\text { Panel: time-invariant } \\
\text { Maturity }\end{array}$ & & & & & & \\
gb_volume (in years) & 250 & 6.2407 & 3.2921 & 1.9973 & 5.0055 & 30.0192 \\
cb_volume (bn USD) & 250 & 0.6695 & 0.8690 & 0.0015 & 0.3235 & 5.5760 \\
\hline
\end{tabular}

This table reports summary statistics on time-variant and time-invariant green bond characteristics. The entire data sample contains 92,774 daily observations from 250 bond triplets ( 250 green bonds matched with 500 conventional bonds). The variables are defined in Table 12

${ }^{\mathrm{a}}$ Maturity of the green bond at issuance

sample size from 1248 to 250 during the whole matching process when adding matching criteria step by step in Table 11 .

In total, our sample comprises 92,774 daily observations for the period from 2011 to 2020 and for various variables defined in Table 12. On average, the yield and liquidity difference between green bonds and comparable conventional bonds, are both close to zero (see Table 2). The maturity of green bonds has an average value of 4.20 years and ranges from less than one month to more than 28 years. Green bonds have a maximum yield of $23 \%$ and a minimum of $-0.97 \%$, with a mean of $1.62 \%$. The average issue volume of green bonds is 0.43 billion USD, which is lower than that of comparable conventional bonds ( 0.67 billion USD).

Around half of the green bonds in the final sample are denominated in USD or EUR, while those denominated in currencies such as HKD, MXN, and SGD have a share of less than $1 \%$ (see Table 3). Regarding issuer type, the largest share $(26.80 \%)$ of green bonds are from supranational institutions such as the World Bank and the International Finance Corporation, and financial institutions such as banks. Furthermore, green bonds with an AAA credit rating comprise almost a third of the sample while those with a credit rating lower than A+ have a share of $10 \%$.

Besides basic bond features, we observe information related to external review reports. SPOs are the most popular type of external reviews. 196 out of 250 green bonds are assigned to an SPO. Among the green bonds with an SPO, 49 are categorized as dark green, and 52 as medium green. However, the other 95 have no specific shade of green, despite the existence of an SPO. Moreover, no green bond is classified as brown by SPO providers in our sample. ${ }^{17}$ Verification reports and

\footnotetext{
17 This does not mean that our sample is not representative. SPO providers seldom release a negative shade. For instance, CICERO's SPOs are graded as dark green or medium green in most instances, if there is a clear evaluation result.
} 
Table 3 Descriptive statistics for categorical variables

\begin{tabular}{|c|c|c|c|c|c|}
\hline Variable & Obs. & Relative & Variable & Obs. & Relative \\
\hline$S P O$ & & & $\mathrm{CNY}$ & 10 & 4.00 \\
\hline Yes & 196 & 78.40 & EUR & 72 & 28.80 \\
\hline \multirow[t]{2}{*}{ No } & 54 & 21.60 & GBP & 3 & 1.20 \\
\hline & & & HKD & 1 & 0.40 \\
\hline Shade & & & INR & 4 & 1.60 \\
\hline Dark green & 49 & 19.60 & JPY & 5 & 2.00 \\
\hline Medium green & 52 & 20.80 & MXN & 1 & 0.40 \\
\hline No shade & 95 & 38.00 & NOK & 6 & 2.40 \\
\hline \multirow[t]{2}{*}{ No SPO } & 54 & 21.60 & SEK & 48 & 19.20 \\
\hline & & & SGD & 1 & 0.40 \\
\hline Verification & & & TRY & 3 & 1.20 \\
\hline Yes & 51 & 20.40 & USD & 52 & 20.80 \\
\hline No & 199 & 79.60 & ZAR & 6 & 2.40 \\
\hline CBI_certification & & & issuer_type & & \\
\hline Yes & 17 & 6.80 & Agency & 46 & 18.40 \\
\hline \multirow[t]{2}{*}{ No } & 233 & 93.20 & Corporate & 47 & 18.80 \\
\hline & & & Financial & 67 & 26.80 \\
\hline green_rating & & & Municipal & 21 & 8.40 \\
\hline Yes & 10 & 4.00 & Sovereign & 2 & 0.80 \\
\hline No & 240 & 96.00 & Supranational & 67 & 26.80 \\
\hline Seniority $^{\mathrm{a}}$ & & & credit_rating & & \\
\hline MTG & 8 & 3.20 & AAA & 79 & 31.60 \\
\hline SEC & 2 & 0.80 & $\mathrm{AA}+$ & 11 & 4.40 \\
\hline SR & 203 & 81.20 & AA & 13 & 5.20 \\
\hline SRBN & 4 & 1.60 & $\mathrm{AA}-$ & 12 & 4.80 \\
\hline SRP & 15 & 6.00 & A+ & 15 & 6.00 \\
\hline SRSEC & 4 & 1.60 & A & 5 & 2.00 \\
\hline \multirow[t]{2}{*}{ UN } & 14 & 5.60 & A- & 4 & 1.60 \\
\hline & & & $\mathrm{BBB}+$ & 8 & 3.20 \\
\hline Currency & & & BBB & 4 & 1.60 \\
\hline AUD & 23 & 9.20 & BBB- & 4 & 1.60 \\
\hline $\mathrm{CAD}$ & 7 & 2.80 & $\mathrm{NR}^{\mathrm{b}}$ & 95 & 38.00 \\
\hline $\mathrm{CHF}$ & 8 & 3.20 & & & \\
\hline
\end{tabular}

This table contains summary statistics on the green bond sample of this study. The entire data sample contains 92,774 daily observations from 250 bond triplets ( 250 green bonds matched with 500 conventional bonds). The variables are defined in Table 12

$M T G$ senior secured and mortgage backed, SEC secured, $S R$ senior unsecured, $S R B N$ senior non-preferred, $S R P$ senior preferred, SRSEC senior secured, $U N$ unsecured

${ }^{a}$ Seniority indicates the combined information on bond seniority and collateral status on Eikon

${ }^{b} \mathrm{NR}$ means that the green bond does not have a S\&P equivalent crediting rating on Eikon 
the CBI certification appear to be less popular than SPOs in the green bond market. In our final sample, $20.40 \%$ green bonds have a verification report and only $6.80 \%$ have a certification from CBI. Only ten green bonds have a green rating from traditional credit rating agencies. Eight green bonds reveal an 'excellent' green rating from Moody and two green bonds a 'Green 1' green rating from Japan Credit Rating Agency (JCR).

\section{Empirical methodology}

\subsection{Estimating the green bond premium}

To eliminate the impact of the liquidity difference on the green bond premium, we regress the yield difference on the liquidity difference in a hybrid model (see e.g., Mundlak 1978; Bell and Jones 2015):

$$
\Delta r_{i t}=\beta_{0}+\beta_{1}\left(\Delta L_{i t}-\overline{\Delta L_{i}}\right)+\beta_{2} \overline{\Delta L_{i}}+\left(u_{i}+e_{i t}\right)
$$

where $\overline{\Delta L_{i}}$ is the mean of the liquidity difference within a specific bond $i, u_{i}$ represents the individual error term, and $e_{i t}$ is the overall error term. In the hybrid model, the variable $\Delta L_{i t}$ is decomposed into a within-effects component $\Delta L_{i t}-\overline{\Delta L_{i}}$ and a between-effects component $\overline{\Delta L_{i}}$. The estimate of the within-effects $\beta_{1}$ is unbiased, regardless whether $u_{i}$ is correlated with $\Delta L_{i t}$ (Schunck 2013; Bell and Jones 2015). Moreover, it is also possible to estimate the between-effects $\beta_{2}$ in the hybrid model. Given that the bonds in this study are collected from various countries and traded on various platforms, there could be between-effects in the bond pricing dynamics.

We further subtract the influence of the liquidity difference from the yield difference and estimate the green bond premium as follows:

$$
\hat{p_{i t}}=\Delta r_{i t}-\hat{\beta}_{1}\left(\Delta L_{i t}-\overline{\Delta L_{i}}\right)-\hat{\beta_{2}} \overline{\Delta L_{i}}
$$

where $\hat{\beta}_{1}$ and $\hat{\beta}_{2}$ are estimated coefficients from the hybrid model in Eq. (11). In this way, the estimated green bond premium $\hat{p_{i t}}$ varies across different bonds and over time.

\subsection{Determinants of the green bond premium}

We investigate the determinants of the green bond premium in another hybrid regression model. Besides its advantages mentioned in the previous subsection, the hybrid model enables incorporating time-invariant variables (Bell and Jones 2015). Since some time-invariant variables related to external reviews such as SPO and shade are of particular interest and important for testing our hypotheses, we adopt the hybrid model to investigate the determinants. We run the model with the time-variant green bond premium $\hat{p_{i t}}$ extracted from the initial hybrid regression in Eq. (11) as the dependent variable: 
Table 4 Hybrid model to extract the green bond premium

\begin{tabular}{lll}
\hline & Coef. & Robust SE \\
\hline$\Delta L_{i t}-\overline{\Delta L_{i}}$ & $0.2882^{* * *}$ & 0.0953 \\
$\overline{\Delta L_{i}}$ & $0.9210^{* *}$ & 0.3754 \\
${ }_{\text {cons }}$ & $0.0094^{* *}$ & 0.0039 \\
$N$ & 92,774 & \\
Wald $c h i^{2}$ & 43.7700 & \\
Prob $>c h i^{2}$ & 0.0000 & \\
Rho & 0.4968 & \\
\hline
\end{tabular}

This table contains the results of the hybrid model explaining the difference in the yields of green and matched conventional bonds by the variation of liquidity. $\Delta L_{i t}-\overline{\Delta L_{i}}$ measures the within-variability in liquidity, i.e., at the bond level. $\overline{\Delta L_{i}}$ represents the between-variability to capture cross-sectional effects. _cons represents the estimate for the average overall green bond premium in our sample. The full sample includes 92,774 daily observations for 250 bond triplets. Standard errors are cluster-robust at the issuer level

${ }^{*} p<.1,{ }^{* *} p<.05,{ }^{* * *} p<.01$

*indicates the significance level of the coefficients: $* \mathrm{p}<.1$, $* * \mathrm{p}<0.05, * * * \mathrm{p}<0.01$

$$
\hat{p_{i t}}=\gamma_{0}+\gamma_{1}\left(T V_{i t}-\overline{T V_{i}}\right)+\gamma_{2} \overline{T V_{i}}+\gamma_{3} T I_{i}+\left(u_{i}+e_{i t}\right) .
$$

$T V_{i t}$ represents time-variant control variables, i.e., maturity and gb_yield. Accordingly, each time-variant variable is transformed into two variables (one in the within-effects vector $T V_{i t}-\overline{T V_{i}}$ and the other in the between-effects vector $\overline{T V_{i}}$ ) in the hybrid regression. $T I_{i}$ comprises time-invariant variables of interest, namely dummy or categorical variables regarding the existence of a specific type of external review or related greenness evaluation results. Moreover, $T I_{i}$ includes other timeinvariant control variables related to basic bond features such as currency, issuer type, and credit_rating that have been extensively investigated in earlier studies (see e.g., Zerbib 2019).

\section{Results}

\subsection{The green bond premium}

This section tests our first hypothesis of whether investors trade green bonds at a premium in the secondary market in general. Accordingly, we apply the hybrid model in Eq. (11). Thereby, we estimate the green bond premium for each green bond on each trading day following Eq. (12). The variation of liquidity difference at the bond 


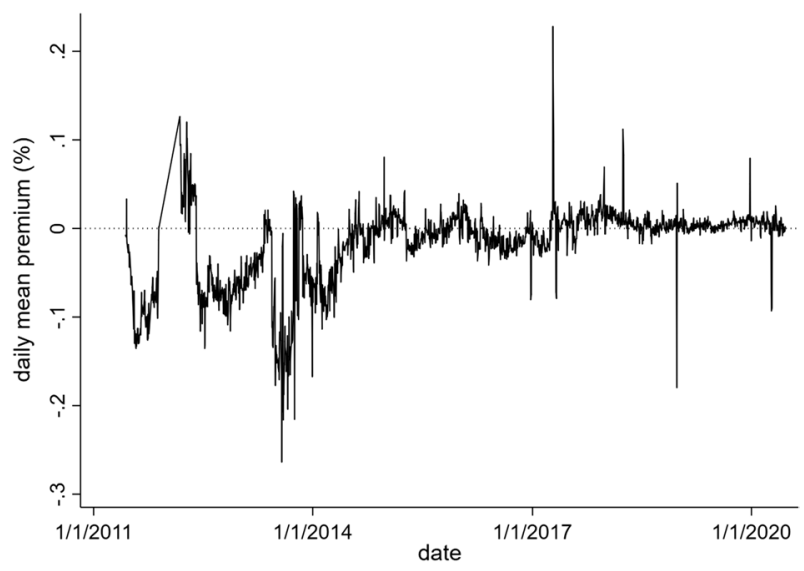

Fig. 1 Premium development over time. This figure shows the daily, cross-sectional average green bond premium over time

level explains part of the variation of yield difference as the coefficient of $\Delta L_{i t}-\overline{\Delta L_{i}}$ which is significant at the $1 \%$ level (see Table 4 ). Therefore, it is important to control for the liquidity difference when estimating the green bond premium. The significance of the coefficient of the second term $\overline{\Delta L_{i}}$ at the 5\% level shows the existence of between-effects among different bonds. Moreover, the constant term (0.94 BP) in Table 4 is significant at the $5 \%$ level. This constant term is the estimate for the expected value of the overall green bond premium. Considering Eqs. (11) and (12), this constant term is the estimate for the expected value of $\beta_{0}$ of Eq. 11. Thus, the expected overall green bond premium in our model is the average over the premiums of each green bond. Based on the significances presented in Table 4, we find statistical evidence that supports H1 stating that investors trade green bonds, on average, at a premium over comparable conventional bonds.

To illustrate the time-variant green bond premium, we calculate the cross-sectional average of $\hat{p_{i t}}$ on a daily basis to show the general development of the estimated green bond premium over time (see Fig. 1). ${ }^{18}$ The green bond premium was rather volatile in earlier years and became stable in recent years. ${ }^{19}$ It appears that overall the green bond premium was more likely to be negative before 2015, and increased in the following years.

\subsection{Shades of green and time-variant green bond premium}

We continue with the test of hypotheses $\mathrm{H} 2$ to $\mathrm{H} 4$ regarding whether an external review and the greenness of green bonds impact on the premium in the secondary

\footnotetext{
18 The spikes and dips are reasonable, as for some trading days, there are fewer daily observations.

19 It should be noted that the panel dataset is unbalanced and there are fewer green bonds in the first few years.
} 
market. Therefore, we run hybrid model regressions defined in Eq. (13) with robust standard errors clustered at the issuer level.

To test Hypothesis 2, we include four dummy variables (SPO, green_rating, verification, and CBI_certification) indicating whether a specific type of external review is available, besides control variables in the hybrid model (Model Hybridl). The coefficients of SPO and verification are both significantly positive, at the 1 and 5\% level, respectively. Thus, green bonds with an SPO and a verification face higher premiums than green bonds without such external reviews. In our theoretical framework, this finding supports the hypothesis that non-financial disclosure from external reviewers increases transparency substantially and there is a sufficiently large group of investors with an $\alpha>0$ that influence equilibrium prices of green bond investments. However, we cannot find evidence that a CBI certification or a green rating makes an additional marginal contribution to a higher green bond premium. Therefore, even though there are four types of external reviews available in the green bond market, we find that the more popular type of external reviews, i.e., SPOs and verifications, are really valued by green bond investors.

Furthermore, we include an interaction term (maturity $* \overline{S P O}$ ) of maturity and $\overline{S P O}(=1-S P O)$ in Model Hybrid2 to test whether the influence of an SPO is timedependent (H3). In a hybrid model, the time-variant interaction term is transformed into two terms, namely the within-effects term $\left(d \_\right.$maturity $\left.* \overline{S P O}\right)$, denoted by the prefix 'd', and the between-effects term ( $m$ _maturity $* \overline{S P O})$, denoted by the prefix ' $m$ '. Nevertheless, the coefficient of the within-effects term is not significant in the entire sample and thus does not support $\mathrm{H} 3$ stating that the premium of green bonds without an SPO will increase as investors become more familiar with these bonds.

Model Hybrid3 takes advantages of the classification of SPOs into different categories, namely dark_green, medium_green, no_shade, and no_SPO, according to external reviewers' evaluation results. The coefficients of the different shades of green in Model Hybrid3 are all significantly positive at the $1 \%$ level compared to the no_SPO category (reference category), with that of dark_green being the highest (5.36 BP) and no_shade the lowest (3.30 BP). In line with H2, green bonds reviewed by an SPO provider show significantly higher premiums compared to green bonds without an SPO for all shades of green. More specifically, green bonds with a "better" shade of green tend to have a higher green bond premium, which is in accordance with H4. Thus, investors also integrate the greenness of green bonds, as suggested by an SPO provider, into the pricing. Investors are willing to pay a higher premium if the green bond has proved to contribute seriously to climate adaptation and mitigation.

To investigate the significance of the differences in the impact on the premium among different shades of green, we analyze the impact of the level of greenness on the green bond premium in the subsample of green bonds with an SPO. Accordingly, we run the estimation of Model Hybrid4, Table 5, on the subsample of green bonds with an SPO. When no_shade is taken as the reference category, the coefficient of dark_green is significantly positive at the 5\% level, while that of medium_green is not significant. Thus, investors trade a 'dark green'-shaded green bond at a significantly higher premium than ones with no shade. This finding confirms our theoretical expectation that investors appreciate a higher level of greenness, and supports 
Table 5 Determinants of the green bond premium: main hybrid models

\begin{tabular}{|c|c|c|c|c|c|}
\hline & & Hybrid1 & Hybrid2 & Hybrid3 & Hybrid4 \\
\hline \multirow[t]{4}{*}{$\mathrm{H} 2$} & SPO & $\begin{array}{r}0.0355^{* * *} \\
(0.0126)\end{array}$ & $\begin{array}{l}0.0425^{*} \\
\quad(0.0231)\end{array}$ & & \\
\hline & Verification & $\begin{array}{l}0.0246^{* *} \\
(0.0099)\end{array}$ & $\begin{array}{l}0.0248^{* *} \\
(0.0100)\end{array}$ & $\begin{array}{l}0.0255^{* * * *} \\
(0.0095)\end{array}$ & \\
\hline & $\begin{array}{l}\text { CBI_certifica- } \\
\text { tion }\end{array}$ & $\begin{array}{r}-0.0257 \\
(0.0261)\end{array}$ & $\begin{array}{r}-0.0260 \\
(0.0258)\end{array}$ & $\begin{array}{r}-0.0244 \\
(0.0264)\end{array}$ & \\
\hline & green_rating & $\begin{array}{l}0.0179 \\
\quad(0.0120)\end{array}$ & $\begin{array}{l}0.0187 \\
\quad(0.0116)\end{array}$ & $\begin{array}{l}0.0210^{*} \\
\quad(0.0112)\end{array}$ & \\
\hline \multirow[t]{2}{*}{$\mathrm{H} 3$} & \multicolumn{2}{|c|}{$d \_$maturity $* \overline{S P O}$} & $\begin{array}{l}-0.0070 \\
(0.0062)\end{array}$ & & \\
\hline & \multicolumn{2}{|c|}{$m \_$maturity $* \overline{S P O}$} & $\begin{array}{l}0.0018 \\
\quad(0.0037)\end{array}$ & & \\
\hline \multirow[t]{3}{*}{$\mathrm{H} 4$} & \multicolumn{2}{|l|}{ dark_green } & & $\begin{array}{l}0.0536^{* * *} \\
(0.0157)\end{array}$ & $\begin{array}{l}0.0227^{* *} \\
(0.0094)\end{array}$ \\
\hline & \multicolumn{2}{|l|}{ medium_green } & & $\begin{array}{l}0.0376^{* * *} \\
(0.0145)\end{array}$ & $\begin{array}{l}0.0076 \\
\quad(0.0093)\end{array}$ \\
\hline & \multicolumn{2}{|l|}{ no_shade } & & $\begin{array}{l}0.0330^{* * *} \\
(0.0126)\end{array}$ & \\
\hline \multirow[t]{5}{*}{ Controls } & d_maturity & $\begin{array}{l}0.0076 \\
\quad(0.0052)\end{array}$ & $\begin{array}{l}0.0103^{*} \\
\quad(0.0055)\end{array}$ & $\begin{array}{l}0.0076 \\
\quad(0.0052)\end{array}$ & $\begin{array}{l}0.0131^{* *} \\
\quad(0.0061)\end{array}$ \\
\hline & d_gb_yield & $\begin{array}{r}-0.0257^{* *} \\
(0.0131)\end{array}$ & $\begin{array}{r}-0.0262^{* *} \\
(0.0131)\end{array}$ & $\begin{array}{r}-0.0257^{* *} \\
(0.0131)\end{array}$ & $\begin{array}{r}-0.0366^{* *} \\
(0.0156)\end{array}$ \\
\hline & m_maturity & $\begin{array}{r}-0.0026^{* *} \\
(0.0012)\end{array}$ & $\begin{array}{r}-0.0029^{* *} \\
(0.0014)\end{array}$ & $\begin{array}{r}-0.0026^{* *} \\
(0.0012)\end{array}$ & $\begin{array}{r}-0.0024^{*} \\
(0.0013)\end{array}$ \\
\hline & m_gb_yield & $\begin{array}{l}0.0112 \\
\quad(0.0071)\end{array}$ & $\begin{array}{l}0.0113 \\
\quad(0.0072)\end{array}$ & $\begin{array}{l}0.0100 \\
\quad(0.0076)\end{array}$ & $\begin{array}{l}0.0151 \\
\quad(0.0096)\end{array}$ \\
\hline & gb_volume & $\begin{array}{r}-0.0173 \\
(0.0139)\end{array}$ & $\begin{array}{r}-0.0168 \\
(0.0142)\end{array}$ & $\begin{array}{r}-0.0152 \\
\quad(0.0131)\end{array}$ & $\begin{array}{r}-0.0245^{*} \\
(0.0142)\end{array}$ \\
\hline \multirow[t]{5}{*}{ issuer_type } & agency & $\begin{array}{r}-0.0175^{*} \\
(0.0098)\end{array}$ & $\begin{array}{r}-0.0186^{*} \\
(0.0100)\end{array}$ & $\begin{array}{r}-0.0161 \\
(0.0106)\end{array}$ & $\begin{array}{l}0.0013 \\
\quad(0.0122)\end{array}$ \\
\hline & Financial & $\begin{array}{l}0.0327^{* *} \\
\quad(0.0163)\end{array}$ & $\begin{array}{l}0.0326^{* *} \\
(0.0163)\end{array}$ & $\begin{array}{l}0.0343^{* *} \\
(0.0161)\end{array}$ & $\begin{array}{l}0.0340^{* *} \\
(0.0171)\end{array}$ \\
\hline & Municipal & $\begin{array}{r}-0.0067 \\
(0.0109)\end{array}$ & $\begin{array}{r}-0.0075 \\
(0.0112)\end{array}$ & $\begin{array}{r}-0.0067 \\
(0.0109)\end{array}$ & $\begin{array}{l}0.0020 \\
\quad(0.0104)\end{array}$ \\
\hline & Sovereign & $\begin{array}{l}0.0185 \\
\quad(0.0376)\end{array}$ & $\begin{array}{l}0.0175 \\
\quad(0.0373)\end{array}$ & $\begin{array}{l}0.0297 \\
\quad(0.0372)\end{array}$ & $\begin{array}{l}0.0527 \\
\quad(0.0381)\end{array}$ \\
\hline & Supranational & $\begin{array}{r}-0.0041 \\
(0.0100)\end{array}$ & $\begin{array}{r}-0.0048 \\
(0.0103)\end{array}$ & $\begin{array}{l}0.0032 \\
\quad(0.0110)\end{array}$ & $\begin{array}{l}0.0004 \\
\quad(0.0127)\end{array}$ \\
\hline \multirow[t]{4}{*}{ credit_rating } & AAA & $\begin{array}{r}0.0745^{* * *} \\
(0.0269)\end{array}$ & $\begin{array}{r}0.0748^{* * * *} \\
(0.0270)\end{array}$ & $\begin{array}{l}0.0676^{* *} \\
(0.0270)\end{array}$ & $\begin{array}{l}0.0376 \\
\quad(0.0284)\end{array}$ \\
\hline & $\mathrm{AA}+$ & $\begin{array}{l}0.0573^{*} \\
\quad(0.0295)\end{array}$ & $\begin{array}{l}0.0574^{*} \\
\quad(0.0296)\end{array}$ & $\begin{array}{l}0.0551^{*} \\
(0.0299)\end{array}$ & $\begin{array}{l}0.0262 \\
\quad(0.0278)\end{array}$ \\
\hline & AA & $\begin{array}{l}0.0023 \\
\quad(0.0221)\end{array}$ & $\begin{array}{l}0.0027 \\
\quad(0.0223)\end{array}$ & $\begin{array}{r}-0.0029 \\
(0.0238)\end{array}$ & $\begin{array}{r}-0.0001 \\
(0.0240)\end{array}$ \\
\hline & $\mathrm{AA}-$ & $\begin{array}{l}0.0484 \\
\quad(0.0296)\end{array}$ & $\begin{array}{l}0.0482 \\
\quad(0.0297)\end{array}$ & $\begin{array}{l}0.0486 \\
\quad(0.0302)\end{array}$ & $\begin{array}{l}0.0417 \\
\quad(0.0294)\end{array}$ \\
\hline
\end{tabular}


Table 5 (continued)

\begin{tabular}{|c|c|c|c|c|}
\hline & Hybrid1 & Hybrid2 & Hybrid3 & Hybrid4 \\
\hline $\mathrm{A}+$ & $\begin{array}{l}0.0106 \\
\quad(0.0357)\end{array}$ & $\begin{array}{l}0.0114 \\
\quad(0.0358)\end{array}$ & $\begin{array}{l}0.0091 \\
\quad(0.0360)\end{array}$ & $\begin{array}{l}0.0248 \\
\quad(0.0398)\end{array}$ \\
\hline A & $\begin{array}{l}-0.0055 \\
(0.0380)\end{array}$ & $\begin{array}{r}-0.0054 \\
(0.0379)\end{array}$ & $\begin{array}{r}-0.0141 \\
(0.0381)\end{array}$ & $\begin{array}{r}-0.0104 \\
\quad(0.0414)\end{array}$ \\
\hline A- & $\begin{array}{l}0.0976^{* * * *} \\
(0.0303)\end{array}$ & $\begin{array}{r}0.0988^{* * * *} \\
(0.0313)\end{array}$ & $\begin{array}{l}0.0955^{* * * *} \\
(0.0286)\end{array}$ & $\begin{array}{l}0.0786^{* * * *} \\
(0.0294)\end{array}$ \\
\hline $\mathrm{BBB}+$ & $\begin{array}{l}0.0328 \\
\quad(0.0215)\end{array}$ & $\begin{array}{l}0.0334 \\
\quad(0.0214)\end{array}$ & $\begin{array}{l}0.0321 \\
\quad(0.0218)\end{array}$ & $\begin{array}{l}0.0546^{* *} \\
(0.0228)\end{array}$ \\
\hline $\mathrm{BBB}$ & $\begin{array}{l}0.0137 \\
\quad(0.0209)\end{array}$ & $\begin{array}{l}0.0140 \\
\quad(0.0208)\end{array}$ & $\begin{array}{l}0.0070 \\
(0.0204)\end{array}$ & $\begin{array}{r}-0.0055 \\
(0.0244)\end{array}$ \\
\hline NR & $\begin{array}{l}0.0381^{*} \\
\quad(0.0225)\end{array}$ & $\begin{array}{l}0.0384^{*} \\
\quad(0.0225)\end{array}$ & $\begin{array}{l}0.0338 \\
\quad(0.0229)\end{array}$ & $\begin{array}{l}0.0184 \\
\quad(0.0246)\end{array}$ \\
\hline Seniority & Yes & Yes & Yes & Yes \\
\hline Currency & Yes & Yes & Yes & Yes \\
\hline _cons & $\begin{array}{r}-0.0442 \\
(0.0404)\end{array}$ & $\begin{array}{c}-0.0498 \\
(0.0440)\end{array}$ & $\begin{array}{c}-0.0412 \\
(0.0429)\end{array}$ & $\begin{array}{l}0.0206 \\
\quad(0.0443)\end{array}$ \\
\hline$N$ & 92,774 & 92,774 & 92,774 & 68,215 \\
\hline Rho & 0.4971 & 0.4993 & 0.4971 & 0.4871 \\
\hline
\end{tabular}

This table reports the results of the hybrid model regressions with the green bond premium $\hat{p_{i t}}$ as the dependent variable. Standard errors are cluster-robust at the issuer level and provided in parentheses. The full sample includes 92,774 daily observations for 250 matched bond triplets. The subsample in Model Hybrid4 only includes 68,215 daily observations for 196 green bonds with an SPO

${ }^{*} p<.1,{ }^{* *} p<.05,{ }^{* * *} p<.01$

H4 to some extent. The pricing effect of the greenness level on the green bond premium prevails only for the dark_green vs. no_shade comparison, but is insignificant for the dark_green vs. medium_green comparison. ${ }^{20}$

Besides the above findings from variables that are of special interest, it is noteworthy that the coefficient of $d \_$maturity is significantly positive at the $5 \%$ level in Model Hybrid4 (the subsample analysis). This pattern indicates that the premium of green bonds with an SPO is positively related to their maturity. In other words, as green bonds with an SPO have been traded on the market for a longer time (the maturity decreases), the green bond premium decreases. This fact provides some weak supporting evidence in the context of $\mathrm{H} 3$ to the extent that the premiums of green bonds with an SPO diminish, when the green bonds approach maturity. In

\footnotetext{
20 This is analyzed by making medium green the reference category and redoing the regression. Given the absence of a significant result, the corresponding table is omitted.
} 
Table 6 Hybrid model to extract the green bond premiumrobustness check

\begin{tabular}{lll}
\hline & Coef. & Robust SE \\
\hline$\Delta L_{i t}-\overline{\Delta L_{i}}$ & $0.4603^{* * *}$ & 0.1309 \\
$\overline{\Delta L_{i}}$ & $0.8898^{* * *}$ & 0.3364 \\
_cons & $0.0065^{*}$ & 0.0037 \\
$N$ & 89,285 & \\
Wald $c h i^{2}$ & 25.9900 & \\
Prob $>c h i^{2}$ & 0.0000 & \\
Rho & 0.4917 &
\end{tabular}

This table contains the results of the hybrid model explaining the difference in the yields of green and matched conventional bonds by the variation of liquidity for the restricted sample. $\Delta L_{i t}-\overline{\Delta L_{i}}$ measures the within-variability in the liquidity, i.e., at the bond level. $\overline{\Delta L_{i}}$ represents the between-variability to capture cross-sectional effects. The restricted sample includes only 89,285 daily observations for 216 bond triplets, due to stricter data filters. Standard errors are cluster-robust at the issuer level

${ }^{*} p<.1,{ }^{* *} p<.05,{ }^{* * *} p<.01$

*indicates the significance level of the coefficients: ${ }^{*} \mathrm{p}<.1$, $* * \mathrm{p}<0.05, * * * \mathrm{p}<0.01$

Table 7 Descriptive statistics for the green bond premium-robustness check

\begin{tabular}{|c|c|c|c|c|c|c|c|}
\hline & Obs. & Mean & Std. & $\mathrm{p}$-value & Min & Median & $\operatorname{Max}$ \\
\hline \multicolumn{8}{|c|}{ Panel: smaller sample } \\
\hline$\hat{p_{i t}}$ & 89,285 & -0.0002 & 0.1058 & 0.4881 & -0.9698 & 0.0024 & 0.9509 \\
\hline \multicolumn{8}{|c|}{ Panel: Zerbib's approach } \\
\hline$\hat{p}_{i}$ & 250 & 0.0095 & 0.0820 & 0.0678 & -0.4799 & 0.0031 & 0.6327 \\
\hline
\end{tabular}

The restricted sample includes only 89,285 daily observations for 216 bond triplets, due to stricter data filters. The green bond premium $\hat{p_{i t}}$ is estimated by Eq. 12. The green bond premium $\hat{p}_{i}$ is extracted from the fixed-effects model in Eq. 14. p-value is from a t-test identifying whether $\hat{p_{i t}}$ or $\hat{p_{i}}$ is significantly different from zero

terms of informational transaction cost theory, the documented premium difference pattern can be explained by searching costs for information, which is already provided by SPOs. The more mature a green bond becomes, the more information on the respective greenness is available. This reduces information costs and therefore, the requirement of higher yields to compensate for idiosyncratic greenness risk and to cover search costs.

Regarding the other control variables, we observe the following. The coefficient of $d \_g b \_y i e l d$ indicates that the green bond yield is negatively related to the green bond premium. As regards issuer type, green bonds issued by agencies have a lower premium (in Model Hybridl - Hybrid2), while those issued by financial institutions enjoy a significantly higher premium compared to those issued by corporates (in all model specifications). Moreover, green bonds with a credit rating of AAA or AA+, which constitute a considerable percentage of the sample, evidently enjoy a higher 
premium in the full sample regressions (Model Hybridl - Hybrid3), which may suggest that green bond investors prefer those with the highest credit ratings. Investors are also interested in green bonds with a A- rating, as all the coefficients are significantly positive in different model setups.

\subsection{Additional analyses}

To gauge the robustness of our results from the main models, we adjust the selection filters of yield data and redo the matching process. We limit the maximum bid-ask spread to $30 \mathrm{BP}$ (instead of $50 \mathrm{BP}$ in the main matching process), so as to exclude daily observations of less liquid bonds. Moreover, we increase the required minimum number of daily observations for each bond triplet to 100 (instead of 50 in the main matching process). These changes in filters result in a reduction of around 3,500 daily observations and a total of 34 bond triplets in the sample.

Similarly, we run the hybrid model in Eq. (11) and extract the green bond premium from Eq. (12) (see Tables 6 and 7). In Table 6, we observe a relatively small intercept term which may indicate an overall small positive premium of $0.64 \mathrm{BP}$ (significant at the $10 \%$ level). We rerun the hybrid model in Eq. (13) to investigate the determinants, and present the regression results for the subsample in Table 8 . The main results for Models Hybridla-Hybrid4a are similar to those of Models Hybrid1-Hybrid4 in Table 5, despite some deviations in the significance levels. Both the coefficients of SPO and verification are significantly positive across different models. Again, all shades of green lead to a higher premium in Model Hybrid3a. Moreover, the coefficient of dark_green remains significantly positive when the hybrid model is run in a subsample of green bonds with an SPO, and thus supports H4. Nevertheless, we still do not find a statistically significant difference when comparing a dark green shade with a medium green one, or a medium green with no clear shade. Lastly, the coefficient of the control variable $d$ _maturity in Model Hybrid4a is also significantly positive, which indicates that the premiums of SPO and non-SPO green bonds converge. Regarding control variables issuer_type and credit_rating, we cannot confirm those findings in the main models with the restricted sample.

Additionally, we rerun the hybrid models in the full sample with robust standard errors clustered at the bond level (instead of at the issuer level in the main models in Table 5) as another robustness check (see Table 9). The overall significance pattern for Models $H y b r i d 1 b-H y b r i d 4 b$ remains relatively stable and robust, compared with the main results.

For a further robustness check, we follow the empirical approach of most comprehensive existing analysis of the green bond premium by Zerbib (2019) to estimate the green bond premium in a fixed-effects model as follows:

$$
\Delta r_{i t}=p_{i}+\beta \Delta L_{i t}+\epsilon_{i t}
$$

where the time-invariant individual effects $p_{i}$ is treated as the green bond premium. The estimated green bond premium $\hat{p}_{i}$ has a mean value of $0.95 \mathrm{BP}$. It is significantly 
Table 8 The green bond premium determinants in the restricted sample

\begin{tabular}{|c|c|c|c|c|c|}
\hline & & Hybrid1a & Hybrid2a & Hybrid3a & Hybrid4a \\
\hline \multirow[t]{4}{*}{$\mathrm{H} 2$} & SPO & $\begin{array}{l}0.0213^{* *} \\
(0.0103)\end{array}$ & $\begin{array}{l}0.0263^{*} \\
\quad(0.0160)\end{array}$ & & \\
\hline & Verification & $\begin{array}{l}0.0150^{*} \\
\quad(0.0080)\end{array}$ & $\begin{array}{l}0.0151^{*} \\
\quad(0.0080)\end{array}$ & $\begin{array}{l}0.0183^{* *} \\
\quad(0.0078)\end{array}$ & \\
\hline & $\begin{array}{l}\text { CBI_certifica- } \\
\text { tion }\end{array}$ & $\begin{array}{r}-0.0250 \\
(0.0265)\end{array}$ & $\begin{array}{r}-0.0251 \\
\quad(0.0263)\end{array}$ & $\begin{array}{r}-0.0218 \\
(0.0270)\end{array}$ & \\
\hline & green_rating & $\begin{array}{l}0.0059 \\
\quad(0.0106)\end{array}$ & $\begin{array}{l}0.0060 \\
(0.0106)\end{array}$ & $\begin{array}{l}0.0127 \\
\quad(0.0107)\end{array}$ & \\
\hline \multirow[t]{2}{*}{$\mathrm{H} 3$} & \multicolumn{2}{|l|}{$d \_$maturity $* \overline{S P O}$} & $\begin{array}{r}-0.0076 \\
(0.0063)\end{array}$ & & \\
\hline & \multicolumn{2}{|l|}{$m \_$maturity $* \overline{S P O}$} & $\begin{array}{l}0.0011 \\
\quad(0.0029)\end{array}$ & & \\
\hline \multirow[t]{3}{*}{$\mathrm{H} 4$} & dark_green & & & $\begin{array}{r}0.0516^{* * *} \\
(0.0157)\end{array}$ & $\begin{array}{r}0.0383^{* * *} \\
(0.0127)\end{array}$ \\
\hline & medium_green & & & $\begin{array}{l}0.0251^{* *} \\
(0.0116)\end{array}$ & $\begin{array}{l}0.0112 \\
\quad(0.0091)\end{array}$ \\
\hline & no_shade & & & $\begin{array}{l}0.0178^{*} \\
(0.0093)\end{array}$ & \\
\hline \multirow[t]{5}{*}{ Controls } & d_maturity & $\begin{array}{l}0.0095^{*} \\
\quad(0.0054)\end{array}$ & $\begin{array}{l}0.0124^{* *} \\
\quad(0.0062)\end{array}$ & $\begin{array}{l}0.0095^{*} \\
(0.0054)\end{array}$ & $\begin{array}{l}0.0147^{* *} \\
(0.0070)\end{array}$ \\
\hline & d_gb_yield & $\begin{array}{r}-0.0236^{* *} \\
(0.0116)\end{array}$ & $\begin{array}{r}-0.0241^{* *} \\
(0.0119)\end{array}$ & $\begin{array}{r}-0.0236^{* *} \\
(0.0116)\end{array}$ & $\begin{array}{r}-0.0325^{* *} \\
(0.0158)\end{array}$ \\
\hline & m_maturity & $\begin{array}{r}-0.0008 \\
(0.0011)\end{array}$ & $\begin{array}{l}-0.0009 \\
(0.0011)\end{array}$ & $\begin{array}{l}-0.0006 \\
(0.0011)\end{array}$ & $\begin{array}{l}0.0001 \\
\quad(0.0012)\end{array}$ \\
\hline & m_gb_yield & $\begin{array}{r}-0.0241^{*} \\
(0.0126)\end{array}$ & $\begin{array}{r}-0.0241^{*} \\
(0.0127)\end{array}$ & $\begin{array}{r}-0.0283^{* *} \\
(0.0128)\end{array}$ & $\begin{array}{r}-0.0400^{* *} \\
(0.0161)\end{array}$ \\
\hline & gb_volume & $\begin{array}{r}-0.0230^{* *} \\
(0.0117)\end{array}$ & $\begin{array}{r}-0.0227^{*} \\
(0.0116)\end{array}$ & $\begin{array}{r}-0.0206^{* *} \\
(0.0103)\end{array}$ & $\begin{array}{r}-0.0296^{* *} \\
(0.0133)\end{array}$ \\
\hline \multirow[t]{5}{*}{ issuer_type } & Agency & $\begin{array}{r}-0.0200 \\
(0.0126)\end{array}$ & $\begin{array}{r}-0.0204 \\
(0.0127)\end{array}$ & $\begin{array}{r}-0.0183 \\
(0.0144)\end{array}$ & $\begin{array}{r}-0.0134 \\
(0.0166)\end{array}$ \\
\hline & Financial & $\begin{array}{l}0.0241 \\
\quad(0.0167)\end{array}$ & $\begin{array}{l}0.0242 \\
\quad(0.0168)\end{array}$ & $\begin{array}{l}0.0262 \\
\quad(0.0164)\end{array}$ & $\begin{array}{l}0.0257 \\
(0.0174)\end{array}$ \\
\hline & Municipal & $\begin{array}{r}-0.0052 \\
(0.0116)\end{array}$ & $\begin{array}{r}-0.0056 \\
(0.0119)\end{array}$ & $\begin{array}{l}-0.0065 \\
\quad(0.0118)\end{array}$ & $\begin{array}{l}-0.0045 \\
(0.0121)\end{array}$ \\
\hline & Sovereign & $\begin{array}{l}0.0129 \\
\quad(0.0416)\end{array}$ & $\begin{array}{l}0.0128 \\
\quad(0.0416)\end{array}$ & $\begin{array}{l}0.0299 \\
(0.0413)\end{array}$ & $\begin{array}{l}0.0478 \\
\quad(0.0416)\end{array}$ \\
\hline & Supranational & $\begin{array}{r}-0.0084 \\
(0.0133)\end{array}$ & $\begin{array}{r}-0.0085 \\
(0.0134)\end{array}$ & $\begin{array}{l}0.0038 \\
\quad(0.0130)\end{array}$ & $\begin{array}{l}0.0010 \\
\quad(0.0125)\end{array}$ \\
\hline \multirow[t]{4}{*}{ credit_rating } & AAA & $\begin{array}{r}-0.0098 \\
(0.0366)\end{array}$ & $\begin{array}{l}-0.0099 \\
(0.0365)\end{array}$ & $\begin{array}{r}-0.0242 \\
(0.0315)\end{array}$ & $\begin{array}{r}-0.0577^{*} \\
(0.0341)\end{array}$ \\
\hline & $\mathrm{AA}+$ & $\begin{array}{r}-0.0240 \\
(0.0370)\end{array}$ & $\begin{array}{r}-0.0238 \\
(0.0369)\end{array}$ & $\begin{array}{r}-0.0286 \\
(0.0325)\end{array}$ & $\begin{array}{r}-0.0597^{*} \\
(0.0326)\end{array}$ \\
\hline & AA & $\begin{array}{r}-0.0646^{*} \\
(0.0359)\end{array}$ & $\begin{array}{r}-0.0646^{*} \\
(0.0359)\end{array}$ & $\begin{array}{r}-0.0754^{* *} \\
(0.0330)\end{array}$ & $\begin{array}{r}-0.0877^{* *} \\
(0.0354)\end{array}$ \\
\hline & $\mathrm{AA}-$ & $\begin{array}{r}-0.0202 \\
(0.0418)\end{array}$ & $\begin{array}{r}-0.0204 \\
(0.0418)\end{array}$ & $\begin{array}{r}-0.0207 \\
(0.0374)\end{array}$ & $\begin{array}{r}-0.0375 \\
(0.0368)\end{array}$ \\
\hline
\end{tabular}


Table 8 (continued)

\begin{tabular}{|c|c|c|c|c|}
\hline & Hybrid1a & Hybrid2a & Hybrid3a & Hybrid4a \\
\hline $\mathrm{A}+$ & $\begin{array}{l}-0.0509 \\
(0.0491)\end{array}$ & $\begin{array}{r}-0.0504 \\
(0.0490)\end{array}$ & $\begin{array}{r}-0.0547 \\
(0.0442)\end{array}$ & $\begin{array}{r}-0.0472 \\
(0.0459)\end{array}$ \\
\hline A & $\begin{array}{r}-0.0536 \\
(0.0470)\end{array}$ & $\begin{array}{r}-0.0536 \\
(0.0470)\end{array}$ & $\begin{array}{l}-0.0702 \\
(0.0468)\end{array}$ & $\begin{array}{r}-0.0833^{*} \\
(0.0498)\end{array}$ \\
\hline$A-$ & $\begin{array}{l}0.0302 \\
\quad(0.0468)\end{array}$ & $\begin{array}{l}0.0308 \\
\quad(0.0470)\end{array}$ & $\begin{array}{l}0.0261 \\
\quad(0.0389)\end{array}$ & $\begin{array}{l}0.0066 \\
\quad(0.0409)\end{array}$ \\
\hline $\mathrm{BBB}+$ & $\begin{array}{l}0.0007 \\
\quad(0.0369)\end{array}$ & $\begin{array}{l}0.0009 \\
\quad(0.0368)\end{array}$ & $\begin{array}{r}-0.0032 \\
(0.0315)\end{array}$ & $\begin{array}{r}-0.0000 \\
(0.0335)\end{array}$ \\
\hline $\mathrm{BBB}$ & $\begin{array}{r}-0.0327 \\
(0.0343)\end{array}$ & $\begin{array}{r}-0.0325 \\
(0.0343)\end{array}$ & $\begin{array}{r}-0.0438 \\
(0.0282)\end{array}$ & $\begin{array}{r}-0.0548^{*} \\
(0.0297)\end{array}$ \\
\hline NR & $\begin{array}{r}-0.0414 \\
(0.0360)\end{array}$ & $\begin{array}{r}-0.0413 \\
(0.0360)\end{array}$ & $\begin{array}{r}-0.0495 \\
(0.0309)\end{array}$ & $\begin{array}{r}-0.0724^{* *} \\
(0.0340)\end{array}$ \\
\hline Seniority & Yes & Yes & Yes & Yes \\
\hline Currency & Yes & Yes & Yes & Yes \\
\hline _cons & $\begin{array}{l}0.0985 \\
\quad(0.0755)\end{array}$ & $\begin{array}{l}0.0942 \\
\quad(0.0735)\end{array}$ & $\begin{array}{c}0.1112( \\
0.0739)\end{array}$ & $\begin{array}{l}0.1771^{*} \\
\quad(0.0913)\end{array}$ \\
\hline$N$ & 89,285 & 89,285 & 89,285 & 65,962 \\
\hline Rho & 0.4810 & 0.4841 & 0.4763 & 0.4764 \\
\hline
\end{tabular}

This table reports the results of the hybrid model regressions with the green bond premium $\hat{p_{i t}}$ as the dependent variable. Standard errors are cluster-robust at the issuer level and provided in parentheses. Due to stricter data filters, this smaller sample includes 89,285 daily observations for 216 bond triplets. For Model Hybrid4a, the subsample includes 65,962 daily observations for 170 green bonds with an SPO

${ }^{*} p<.1,{ }^{* *} p<.05,{ }^{* * *} p<.01$

different from zero at the $10 \%$ level. This value is very close to the intercept terms in the hybrid models (see Tables 4 and 6). Thus, overall we find some evidence that there is in general a small green bond premium.

Lastly, we run additional cross-sectional OLS regressions with the estimated time-invariant individual effects $\hat{p}_{i}$ as the dependent variable to investigate the determinants:

$$
\hat{p}_{i}=\beta_{0}+\beta_{1} B_{i}+\beta_{2} G_{i}+\epsilon_{i}
$$

where $B_{i}$ represents a vector of variables covering basic bond features, and $G_{i}$ is a vector of variables related to information from external review reports. Note that two control variables, namely maturity and gb_yield, can no longer be included in crosssectional OLS regressions. For this reason, we cannot test $\mathrm{H} 3$ regarding whether the impact of external reviews is time-dependent. 
Table 9 Green bond premium determinants for standard errors clustered at the bond level

\begin{tabular}{|c|c|c|c|c|c|}
\hline & & Hybrid1b & Hybrid2b & Hybrid3b & Hybrid4b \\
\hline \multirow[t]{4}{*}{$\mathrm{H} 2$} & SPO & $\begin{array}{l}0.0355^{* *} \\
(0.0163)\end{array}$ & $\begin{array}{l}0.0425^{*} \\
(0.0239)\end{array}$ & & \\
\hline & Verification & $\begin{array}{l}0.0246^{* *} \\
(0.0112)\end{array}$ & $\begin{array}{l}0.0248^{* *} \\
(0.0112)\end{array}$ & $\begin{array}{l}0.0255^{* *} \\
(0.0111)\end{array}$ & \\
\hline & $\begin{array}{l}\text { CBI_certifica- } \\
\text { tion }\end{array}$ & $\begin{array}{r}-0.0257 \\
(0.0281)\end{array}$ & $\begin{array}{r}-0.0260 \\
(0.0278)\end{array}$ & $\begin{array}{r}-0.0244 \\
(0.0280)\end{array}$ & \\
\hline & green_rating & $\begin{array}{l}0.0179 \\
\quad(0.0129)\end{array}$ & $\begin{array}{l}0.0187 \\
\quad(0.0129)\end{array}$ & $\begin{array}{l}0.0210^{*} \\
\quad(0.0128)\end{array}$ & \\
\hline \multirow[t]{2}{*}{$\mathrm{H} 3$} & \multicolumn{2}{|c|}{$d \_$maturity $* \overline{S P O}$} & $\begin{array}{l}-0.0070 \\
(0.0067)\end{array}$ & & \\
\hline & \multicolumn{2}{|c|}{$m \_$maturity $* \overline{S P O}$} & $\begin{array}{l}0.0018 \\
\quad(0.0034)\end{array}$ & & \\
\hline \multirow[t]{3}{*}{$\mathrm{H} 4$} & \multicolumn{2}{|l|}{ dark_green } & & $\begin{array}{r}0.0536^{* * *} \\
(0.0194)\end{array}$ & $\begin{array}{l}0.0227^{*} \\
\quad(0.0126)\end{array}$ \\
\hline & \multicolumn{2}{|l|}{ medium_green } & & $\begin{array}{l}0.0376^{* *} \\
(0.0175)\end{array}$ & $\begin{array}{l}0.0076 \\
\quad(0.0114)\end{array}$ \\
\hline & \multicolumn{2}{|l|}{ no_shade } & & $\begin{array}{l}0.0330^{* *} \\
(0.0165)\end{array}$ & \\
\hline \multirow[t]{5}{*}{ Controls } & d_maturity & $\begin{array}{l}0.0076^{*} \\
(0.0042)\end{array}$ & $\begin{array}{l}0.0103^{* *} \\
(0.0050)\end{array}$ & $\begin{array}{l}0.0076^{*} \\
(0.0042)\end{array}$ & $\begin{array}{l}0.0131^{* *} \\
\quad(0.0054)\end{array}$ \\
\hline & d_gb_yield & $\begin{array}{r}-0.0257^{* *} \\
(0.0111)\end{array}$ & $\begin{array}{r}-0.0262^{* *} \\
(0.0112)\end{array}$ & $\begin{array}{r}-0.0257^{* *} \\
(0.0111)\end{array}$ & $\begin{array}{r}-0.0366^{* *} \\
(0.0146)\end{array}$ \\
\hline & m_maturity & $\begin{array}{r}-0.0026^{* *} \\
(0.0013)\end{array}$ & $\begin{array}{r}-0.0029^{* *} \\
(0.0013)\end{array}$ & $\begin{array}{r}-0.0026^{* *} \\
(0.0013)\end{array}$ & $\begin{array}{r}-0.0024^{*} \\
(0.0015)\end{array}$ \\
\hline & m_gb_yield & $\begin{array}{l}0.0112 \\
\quad(0.0131)\end{array}$ & $\begin{array}{l}0.0113 \\
\quad(0.0130)\end{array}$ & $\begin{array}{l}0.0100 \\
\quad(0.0135)\end{array}$ & $\begin{array}{l}0.0151 \\
\quad(0.0156)\end{array}$ \\
\hline & gb_volume & $\begin{array}{r}-0.0173 \\
(0.0118)\end{array}$ & $\begin{array}{r}-0.0168 \\
(0.0119)\end{array}$ & $\begin{array}{r}-0.0152 \\
(0.0109)\end{array}$ & $\begin{array}{r}-0.0245^{* *} \\
(0.0111)\end{array}$ \\
\hline \multirow[t]{5}{*}{ issuer_type } & Agency & $\begin{array}{r}-0.0175 \\
(0.0131)\end{array}$ & $\begin{array}{r}-0.0186 \\
(0.0133)\end{array}$ & $\begin{array}{r}-0.0161 \\
(0.0138)\end{array}$ & $\begin{array}{l}0.0013 \\
(0.0171)\end{array}$ \\
\hline & Financial & $\begin{array}{l}0.0327^{*} \\
(0.0176)\end{array}$ & $\begin{array}{l}0.0326^{*} \\
(0.0176)\end{array}$ & $\begin{array}{l}0.0343^{*} \\
(0.0177)\end{array}$ & $\begin{array}{l}0.0340^{*} \\
(0.0187)\end{array}$ \\
\hline & Municipal & $\begin{array}{r}-0.0067 \\
(0.0128)\end{array}$ & $\begin{array}{r}-0.0075 \\
(0.0132)\end{array}$ & $\begin{array}{r}-0.0067 \\
(0.0127)\end{array}$ & $\begin{array}{l}0.0020 \\
\quad(0.0122)\end{array}$ \\
\hline & Sovereign & $\begin{array}{l}0.0185 \\
\quad(0.0400)\end{array}$ & $\begin{array}{l}0.0175 \\
\quad(0.0399)\end{array}$ & $\begin{array}{l}0.0297 \\
\quad(0.0406)\end{array}$ & $\begin{array}{l}0.0527 \\
\quad(0.0398)\end{array}$ \\
\hline & Supranational & $\begin{array}{r}-0.0041 \\
(0.0185)\end{array}$ & $\begin{array}{r}-0.0048 \\
(0.0187)\end{array}$ & $\begin{array}{l}0.0032 \\
\quad(0.0184)\end{array}$ & $\begin{array}{l}0.0004 \\
\quad(0.0211)\end{array}$ \\
\hline
\end{tabular}


Table 9 (continued)

\begin{tabular}{|c|c|c|c|c|c|}
\hline & & Hybrid1b & Hybrid2b & Hybrid3b & Hybrid4b \\
\hline \multirow[t]{15}{*}{ credit_rating } & AAA & $\begin{array}{l}0.0745^{* * *} \\
(0.0274)\end{array}$ & $\begin{array}{l}0.0748^{* * *} \\
(0.0274)\end{array}$ & $\begin{array}{l}0.0676^{* *} \\
(0.0275)\end{array}$ & $\begin{array}{l}0.0376 \\
\quad(0.0297)\end{array}$ \\
\hline & $\mathrm{AA}+$ & $\begin{array}{l}0.0573^{* *} \\
(0.0290)\end{array}$ & $\begin{array}{l}0.0574^{* *} \\
(0.0292)\end{array}$ & $\begin{array}{l}0.0551^{*} \\
\quad(0.0297)\end{array}$ & $\begin{array}{l}0.0262 \\
(0.0279)\end{array}$ \\
\hline & AA & $\begin{array}{l}0.0023 \\
\quad(0.0225)\end{array}$ & $\begin{array}{l}0.0027 \\
\quad(0.0225)\end{array}$ & $\begin{array}{r}-0.0029 \\
(0.0241)\end{array}$ & $\begin{array}{r}-0.0001 \\
\quad(0.0251)\end{array}$ \\
\hline & AA- & $\begin{array}{l}0.0484 \\
\quad(0.0308)\end{array}$ & $\begin{array}{l}0.0482 \\
\quad(0.0309)\end{array}$ & $\begin{array}{l}0.0486 \\
\quad(0.0315)\end{array}$ & $\begin{array}{l}0.0417 \\
\quad(0.0304)\end{array}$ \\
\hline & $\mathrm{A}+$ & $\begin{array}{l}0.0106 \\
\quad(0.0358)\end{array}$ & $\begin{array}{l}0.0114 \\
\quad(0.0358)\end{array}$ & $\begin{array}{l}0.0091 \\
\quad(0.0363)\end{array}$ & $\begin{array}{l}0.0248 \\
(0.0401)\end{array}$ \\
\hline & A & $\begin{array}{l}-0.0055 \\
(0.0395)\end{array}$ & $\begin{array}{r}-0.0054 \\
(0.0394)\end{array}$ & $\begin{array}{c}-0.0141 \\
(0.0402)\end{array}$ & $\begin{array}{r}-0.0104 \\
(0.0431)\end{array}$ \\
\hline & $\mathrm{A}-$ & $\begin{array}{l}0.0976^{* * *} \\
(0.0309)\end{array}$ & $\begin{array}{l}0.0988^{* * *} \\
(0.0314)\end{array}$ & $\begin{array}{l}0.0955^{* * *} \\
\quad(0.0294)\end{array}$ & $\begin{array}{l}0.0786^{* * *} \\
\quad(0.0303)\end{array}$ \\
\hline & $\mathrm{BBB}+$ & $\begin{array}{l}0.0328 \\
\quad(0.0214)\end{array}$ & $\begin{array}{l}0.0334 \\
\quad(0.0213)\end{array}$ & $\begin{array}{l}0.0321 \\
\quad(0.0221)\end{array}$ & $\begin{array}{l}0.0546^{* *} \\
\quad(0.0240)\end{array}$ \\
\hline & $\mathrm{BBB}$ & $\begin{array}{l}0.0137 \\
\quad(0.0208)\end{array}$ & $\begin{array}{l}0.0140 \\
\quad(0.0208)\end{array}$ & $\begin{array}{l}0.0070 \\
\quad(0.0204)\end{array}$ & $\begin{array}{l}-0.0055 \\
\quad(0.0247)\end{array}$ \\
\hline & NR & $\begin{array}{l}0.0381 \\
\quad(0.0244)\end{array}$ & $\begin{array}{l}0.0384 \\
\quad(0.0244)\end{array}$ & $\begin{array}{l}0.0338 \\
\quad(0.0249)\end{array}$ & $\begin{array}{l}0.0184 \\
\quad(0.0264)\end{array}$ \\
\hline & Seniority & Yes & Yes & Yes & Yes \\
\hline & Currency & Yes & Yes & Yes & Yes \\
\hline & _cons & $\begin{array}{r}-0.0442 \\
(0.0605)\end{array}$ & $\begin{array}{r}-0.0498 \\
(0.0607)\end{array}$ & $\begin{array}{c}-0.0412 \\
(0.0629)\end{array}$ & $\begin{array}{l}0.0206 \\
(0.0645)\end{array}$ \\
\hline & $N$ & 92,774 & 92,774 & 92,774 & 68,215 \\
\hline & Rho & 0.4971 & 0.4993 & 0.4971 & 0.4871 \\
\hline
\end{tabular}

This table reports the results of the hybrid model regressions with the green bond premium $\hat{p_{i t}}$ as the dependent variable. Standard errors are cluster-robust at the bond level and provided in parentheses. The full sample includes 92,774 daily observations for 250 matched bond triplets. For Model Hybrid4b, the subsample only includes 68,215 daily observations for 196 green bonds with an SPO

${ }^{*} p<.1,{ }^{* *} p<.05,{ }^{* * *} p<.01$ 
Table 10 Green bond premium determinants in an OLS regression approach

\begin{tabular}{|c|c|c|c|c|}
\hline & & OLS1 & OLS2 & OLS3 \\
\hline \multirow[t]{4}{*}{$\mathrm{H} 2$} & SPO & $\begin{array}{r}0.0360^{* * * *} \\
(0.0131)\end{array}$ & & \\
\hline & Verification & $\begin{array}{l}0.0112 \\
\quad(0.0114)\end{array}$ & $\begin{array}{l}0.0119 \\
\quad(0.0112)\end{array}$ & \\
\hline & CBI_certification & $\begin{array}{r}-0.0227 \\
(0.0290)\end{array}$ & $\begin{array}{c}-0.0213 \\
(0.0294)\end{array}$ & \\
\hline & green_rating & $\begin{array}{l}0.0171 \\
\quad(0.0107)\end{array}$ & $\begin{array}{l}0.0192^{*} \\
\quad(0.0107)\end{array}$ & \\
\hline \multirow[t]{3}{*}{$\mathrm{H} 4$} & dark_green & & $\begin{array}{l}0.0521^{* * *} \\
(0.0170)\end{array}$ & $\begin{array}{l}0.0232^{* *} \\
(0.0105)\end{array}$ \\
\hline & medium_green & & $\begin{array}{r}0.0389^{* * *} \\
(0.0143)\end{array}$ & $\begin{array}{l}0.0102 \\
\quad(0.0082)\end{array}$ \\
\hline & no_shade & & $\begin{array}{l}0.0335^{* *} \\
\quad(0.0132)\end{array}$ & \\
\hline Controls & gb_volume & $\begin{array}{r}-0.0212^{*} \\
(0.0124)\end{array}$ & $\begin{array}{r}-0.0189 \\
(0.0118)\end{array}$ & $\begin{array}{r}-0.0236^{* *} \\
(0.0111)\end{array}$ \\
\hline \multirow[t]{5}{*}{ issuer_type } & Agency & $\begin{array}{l}-0.0169 \\
(0.0119)\end{array}$ & $\begin{array}{r}-0.0155 \\
(0.0127)\end{array}$ & $\begin{array}{r}-0.0039 \\
(0.0140)\end{array}$ \\
\hline & Financial & $\begin{array}{l}0.0260^{*} \\
(0.0149)\end{array}$ & $\begin{array}{l}0.0273^{*} \\
(0.0149)\end{array}$ & $\begin{array}{l}0.0251 \\
\quad(0.0158)\end{array}$ \\
\hline & Municipal & $\begin{array}{l}-0.0091 \\
(0.0118)\end{array}$ & $\begin{array}{r}-0.0086 \\
(0.0116)\end{array}$ & $\begin{array}{l}0.0005 \\
\quad(0.0099)\end{array}$ \\
\hline & Sovereign & $\begin{array}{l}-0.0163 \\
(0.0446)\end{array}$ & $\begin{array}{r}-0.0051 \\
(0.0444)\end{array}$ & $\begin{array}{l}0.0242 \\
\quad(0.0452)\end{array}$ \\
\hline & Supranational & $\begin{array}{r}-0.0085 \\
(0.0133)\end{array}$ & $\begin{array}{c}-0.0015 \\
(0.0143)\end{array}$ & $\begin{array}{r}-0.0080 \\
(0.0138)\end{array}$ \\
\hline \multirow[t]{11}{*}{ credit_rating } & AAA & $\begin{array}{l}0.0223 \\
\quad(0.0354)\end{array}$ & $\begin{array}{l}0.0163 \\
\quad(0.0327)\end{array}$ & $\begin{array}{r}-0.0154 \\
(0.0315)\end{array}$ \\
\hline & $\mathrm{AA}+$ & $\begin{array}{r}-0.0050 \\
(0.0350)\end{array}$ & $\begin{array}{c}-0.0071 \\
(0.0320)\end{array}$ & $\begin{array}{r}-0.0335 \\
(0.0294)\end{array}$ \\
\hline & AA & $\begin{array}{r}-0.0471 \\
(0.0344)\end{array}$ & $\begin{array}{r}-0.0518 \\
\quad(0.0322)\end{array}$ & $\begin{array}{r}-0.0602^{*} \\
(0.0313)\end{array}$ \\
\hline & $\mathrm{AA}-$ & $\begin{array}{r}-0.0040 \\
(0.0402)\end{array}$ & $\begin{array}{r}-0.0036 \\
(0.0371)\end{array}$ & $\begin{array}{r}-0.0166 \\
(0.0360)\end{array}$ \\
\hline & $\mathrm{A}+$ & $\begin{array}{r}-0.0267 \\
(0.0477)\end{array}$ & $\begin{array}{c}-0.0281 \\
(0.0450)\end{array}$ & $\begin{array}{l}-0.0166 \\
(0.0472)\end{array}$ \\
\hline & A & $\begin{array}{r}-0.0376 \\
(0.0494)\end{array}$ & $\begin{array}{r}-0.0452 \\
\quad(0.0485)\end{array}$ & $\begin{array}{l}-0.0540 \\
(0.0509)\end{array}$ \\
\hline & A- & $\begin{array}{l}0.0336 \\
\quad(0.0379)\end{array}$ & $\begin{array}{l}0.0317 \\
\quad(0.0329)\end{array}$ & $\begin{array}{l}0.0195 \\
\quad(0.0329)\end{array}$ \\
\hline & $\mathrm{BBB}+$ & $\begin{array}{l}0.0094 \\
\quad(0.0353)\end{array}$ & $\begin{array}{l}0.0085 \\
\quad(0.0316)\end{array}$ & $\begin{array}{l}0.0144 \\
\quad(0.0320)\end{array}$ \\
\hline & $\mathrm{BBB}$ & $\begin{array}{l}-0.0261 \\
\quad(0.0321)\end{array}$ & $\begin{array}{r}-0.0327 \\
(0.0283)\end{array}$ & $\begin{array}{r}-0.0449 \\
\quad(0.0297)\end{array}$ \\
\hline & NR & $\begin{array}{c}-0.0195( \\
0.0324)\end{array}$ & $\begin{array}{r}-0.0231 \\
(0.0290)\end{array}$ & $\begin{array}{r}-0.0333 \\
\quad(0.0292)\end{array}$ \\
\hline & Seniority & Yes & Yes & Yes \\
\hline
\end{tabular}


Table 10 (continued)

\begin{tabular}{lllc}
\hline & OLS1 & OLS2 & OLS3 \\
\hline Currency & Yes & Yes & Yes \\
_cons & 0.0182 & 0.0180 & $0.0741^{*}$ \\
& $(0.0399)$ & $(0.0368)$ & $(0.0442)$ \\
$N$ & 250 & 250 & 196 \\
$R^{2}$ & 0.23 & 0.24 & 0.34 \\
Adjusted $R^{2}$ & 0.08 & 0.08 & 0.19 \\
\hline
\end{tabular}

This table reports the results of the OLS regressions with the green bond premium $\hat{p_{i t}}$ as the dependent variable. The dependent variable is the estimated individual effects $\hat{p}_{i}$ derived from the fixed-effects regression. Standard errors are cluster-robust at the issuer level and provided in parentheses. The full sample includes 250 matched bond triplets. For Model OLS3, the subsample only includes 196 green bonds with an SPO

${ }^{*} p<.1,{ }^{* *} p<.05,{ }^{* * *} p<.01$

Model $O L S \_l$ of Table 10 shows that the coefficient of SPO is significantly positive at the $1 \%$ level. This provides evidence supporting $\mathrm{H} 2$ stating that external review reports have a positive influence on the premium. Regarding CBI_certification, green_rating, and verification, we do not find strong evidence for $\mathrm{H} 2$ except that green_rating is significant at the $10 \%$ level in Model OLS_2. When SPOs with different shades of green are treated separately in Model $O L S \_2$, the coefficient of dark_green, medium_green, and no_shade yield a similar pattern as in the main models and thus support H4. Lastly, the coefficient of dark_green shows significantly higher premium in Model $O L S \_3$. In summary, the OLS regression results support most of our main findings from the hybrid models regarding $\mathrm{H} 2$ and $\mathrm{H} 4$.

\section{Conclusion}

In this paper, we revisit the existence of the green bond premium in a comprehensive dataset and examine systematically the impact of all four different types of external reviews and their greenness evaluation on the bond yields. To estimate the green bond premium, we adopt a strict matching between green and conventional bonds. After the matching process, the final sample contains 250 green bonds matched with 500 conventional ones, and more than 92,774 daily observations from 2011 to 2020. On this sample, we perform a two-step regression procedure based on a hybrid model to elicit the green bond premium and its determinants. The first main finding is that, on average, the expected green bond premium is positive and statistically significant.

However, some green bonds are priced evidently higher than their counterparts. In particular, green bonds with an SPO or a verification c.p. enjoy a higher green bond premium. This relationship indicates that credible and assured non-financial disclosure seems valuable for investors. In particular, investors trade green bonds 
with SPOs at prices that increase with the level of greenness evaluation of the green bond, i.e., a darker shade of green is more likely to have a higher premium. This pattern implies that the shade-of-green methodology adopted by external reviewers has the potential to function as a tool for assessing the greenness of green bonds in a pricing-relevant manner, analogous to credit ratings. Issuers of green bonds can thereby lower the financing costs, at least for such green bonds that finance deeply green projects related to mitigating climate change.

Our results also have significant policy and research implications. Independent external reviews appear to be one of the most important pillars of a healthy green bond market, through reducing information asymmetry between issuers and investors. The importance of external reviews and shade of green methodology in green bond pricing reveals that investors are sensitive to information asymmetry on the green asset market. If more public information regarding the greenness of green bonds is available, the investor base of green assets may be extended as investors have more confidence in green assets and are subject to a lower risk of greenwashing. Thus, a reduction of information asymmetry is indeed crucial to the development of climate finance. For instance, there could be more deliberately designed mandatory rules that foster transparency in the industry besides current voluntary-based industry guidelines such as the GBPs. Easier access to third-party reports and evaluations should be promoted to facilitate communication among market participants. Governmental policies supporting issuers of green bonds to achieve standardized, affordable, and independent greenness assessments may contribute to a prosperous climate finance market. This observations on financial markets also highlight the need for more theoretical and empirical research on green finance aspects. Clearly, our findings are not in line with traditional finance theory. Thus, from a behavioral finance perspective they provide some evidence for a greenness bias in the prices of green bonds. However, a contemporary view on such phenomena is rather to rationalize them, i.e., to view them as rational and not as irrational effects. The theoretical reasoning pursued in this study adheres to such an approach. However, more future research on the rationale - and even the calculus - of impact investors appears to be in urgent need. Moreover, future research may analyze further green pricing anomalies and, if applicable, develop a new asset pricing model for bonds. Furthermore, these results are not limited to the bond market but may be applied to other asset classes.

\section{Appendix}

See Tables 11, 12, 13 and 14 and Fig. 2. 
Table 11 How the sample size is reduced during the matching process

\begin{tabular}{lll}
\hline & Criterium description & Sample size \\
\hline & Initial sample & $\mathbf{1 2 4 8}$ \\
1 & $\begin{array}{l}\text { Same bond structure (i.e. straight conven- } \\
\text { tional bonds) }\end{array}$ & -292 \\
& Same currency type & -74 \\
2 & Same coupon type & -1 \\
3 & Same seniority and collateral status & -67 \\
4 & Same credit rating & -25 \\
5 & Issue amount: 0.25 to 4 times & -66 \\
6 & Issue date: -6 to 6 years & -38 \\
7 & Duration difference: -2 to 2 years & -241 \\
8 & 50 joint daily yield observations & -194 \\
9 & Final sample & $\mathbf{2 5 0}$ \\
\hline
\end{tabular}

This table shows how the sample size is reduced during the matching process step by step. The initial sample size of green bonds is 1248. We extract a complete list of conventional bonds for each green bond issuer and start the matching process from step 1 to step 9

${ }^{\text {a }}$ This requirement means that for 292 green bonds we do not find straight conventional bonds which can be matched with green bonds 
Table 12 Definition of variables

\begin{tabular}{|c|c|}
\hline Variable & Description \\
\hline \multicolumn{2}{|l|}{$H 1$} \\
\hline$\Delta r$ & Yield difference between green bonds and comparable synthetic conventional bonds \\
\hline$\hat{p_{i t}}$ & Green bond premium extracted from the hybrid model in Eq. 11 \\
\hline$\hat{p}_{i}$ & Individual effects extracted from the fixed-effects model in Eq. 14 \\
\hline \multicolumn{2}{|l|}{$\mathrm{H} 2$} \\
\hline SPO & $\begin{array}{l}\text { Binary variable with a value of one if a second-party opinion is assigned to the green } \\
\text { bond, zero otherwise }\end{array}$ \\
\hline Verification & $\begin{array}{l}\text { Binary variable with a value of one if a verification is assigned to the green bond, } \\
\text { zero otherwise }\end{array}$ \\
\hline CBI_certification & $\begin{array}{l}\text { Binary variable with a value of one if a CBI certification is assigned to the green } \\
\text { bond, zero otherwise }\end{array}$ \\
\hline green_rating & $\begin{array}{l}\text { Binary variable with a value of one if the green bond has a green rating from a tradi- } \\
\text { tional credit rating agency, zero otherwise }\end{array}$ \\
\hline \multicolumn{2}{|r|}{${ }$} \\
\hline$\overline{S P O}$ & $\begin{array}{l}\text { Binary variable with a value of one if a second-party opinion is not available, zero } \\
\text { otherwise. } \overline{S P O}=1-S P O\end{array}$ \\
\hline \multicolumn{2}{|l|}{ H4 } \\
\hline shade & $\begin{array}{l}\text { Categorical variable indicating the shade of green. Green bonds are classified into } \\
\text { four categories, namely dark green, medium green, no shade and no SPO. The } \\
\text { default reference category is no SPO }\end{array}$ \\
\hline \multicolumn{2}{|l|}{ Controls } \\
\hline$\Delta L$ & $\begin{array}{l}\text { Liquidity difference between a green bond and its comparable synthetic conventional } \\
\text { bond }\end{array}$ \\
\hline Maturity & Maturity of the green bond \\
\hline gb_yield & Daily bid yield of the green bond \\
\hline gb_volume & Issue volume of the green bond \\
\hline cb_volume & $\begin{array}{l}\text { Issue volume of the synthetic bond. The issue volume of the synthetic bond is calcu- } \\
\text { lated as the mean of the issue volumes of the two conventional bonds ( } c b 1 \text { and } c b 2)\end{array}$ \\
\hline Seniority & $\begin{array}{l}\text { Categorical variable indicating the seniority and the collateral status of the green } \\
\text { bond on Eikon. The reference category is 'unsecured' }\end{array}$ \\
\hline Currency & $\begin{array}{l}\text { Categorical variable indicating which currency the green bond is denominated in. } \\
\text { The reference category is USD }\end{array}$ \\
\hline issuer_type & $\begin{array}{l}\text { Green bond issuers are classified into six categories, such as agency, corporate and } \\
\text { financial institution. The reference category is corporate }\end{array}$ \\
\hline credit_rating & $\begin{array}{l}\text { Credit rating of the green bond. Credit ratings from different rating agencies have } \\
\text { been transformed into the same scale. The reference category is BBB- }\end{array}$ \\
\hline
\end{tabular}

Table 13 Descriptive statistics for the green bond sample before matching-metric variables

\begin{tabular}{lllllll}
\hline Variable & Obs. & Mean & Std. & Min & Median & Max \\
\hline Maturity $^{\text {a (in years) }}$ & 1248 & 7.4109 & 6.2719 & 0.9945 & 5.0055 & 100.0658 \\
gb_volume (bn USD) & 1248 & 0.3000 & 0.5010 & 0.0000 & 0.1029 & 6.6912 \\
\hline
\end{tabular}

This table reports summary statistics on characteristics of the green bond sample before the matching process. The sample includes 1248 green bonds. The variables are defined in Table 12

${ }^{\text {a }}$ Maturity of the green bond at issuance 
Table 14 Descriptive statistics for the green bond sample before matching—categorical variables

\begin{tabular}{|c|c|c|c|c|c|}
\hline Variable & Obs. & Relative & Variable & Obs. & Relative \\
\hline Seniority $^{\mathrm{a}}$ & & & SEK & 148 & 11.86 \\
\hline MTG & 12 & 0.96 & SGD & 4 & 0.32 \\
\hline SEC & 6 & 0.48 & THB & 5 & 0.40 \\
\hline SR & 904 & 72.44 & TRY & 12 & 0.96 \\
\hline SRBN & 11 & 0.88 & TWD & 23 & 1.84 \\
\hline SRP & 20 & 1.60 & USD & 264 & 21.15 \\
\hline SRSEC & 38 & 3.04 & VND & 2 & 0.16 \\
\hline UN & 257 & 20.59 & ZAR & 17 & 1.36 \\
\hline Currency & & & issuer_type & & \\
\hline AUD & 58 & 4.65 & Agency & 183 & 14.66 \\
\hline BRL & 15 & 1.20 & Corporate & 345 & 27.64 \\
\hline CAD & 27 & 2.16 & Financial & 389 & 31.17 \\
\hline $\mathrm{CHF}$ & 18 & 1.44 & Municipal & 67 & 5.37 \\
\hline CNY & 119 & 9.54 & Sovereign & 11 & 0.88 \\
\hline $\mathrm{COP}$ & 1 & 0.08 & Supranational & 253 & 20.27 \\
\hline CZK & 2 & 0.16 & & & \\
\hline DKK & 2 & 0.16 & credit_rating & & \\
\hline EUR & 245 & 19.63 & AAA & 299 & 23.96 \\
\hline GBP & 10 & 0.80 & $\mathrm{AA}+$ & 57 & 4.57 \\
\hline HKD & 20 & 1.60 & AA & 82 & 6.57 \\
\hline HUF & 3 & 0.24 & AA- & 78 & 6.25 \\
\hline IDR & 8 & 0.64 & A+ & 105 & 8.41 \\
\hline INR & 19 & 1.52 & A & 23 & 1.84 \\
\hline JPY & 105 & 8.41 & A- & 50 & 4.01 \\
\hline KRW & 2 & 0.16 & $\mathrm{BBB}+$ & 37 & 2.96 \\
\hline MXN & 12 & 0.96 & BBB & 26 & 2.08 \\
\hline MYR & 54 & 4.33 & BBB- & 14 & 1.12 \\
\hline NGN & 1 & 0.08 & $\mathrm{BB}+$ & 1 & 0.08 \\
\hline $\mathrm{NOK}$ & 21 & 1.68 & BB & 2 & 0.16 \\
\hline NZD & 20 & 1.60 & $\mathrm{~B}+$ & 1 & 0.08 \\
\hline PEN & 2 & 0.16 & B & 2 & 0.16 \\
\hline PHP & 2 & 0.16 & B- & 1 & 0.08 \\
\hline PLN & 3 & 0.24 & $\mathrm{NR}^{\mathrm{b}}$ & 470 & 37.66 \\
\hline RUB & 4 & 0.32 & & & \\
\hline
\end{tabular}

This table reports summary statistics on characteristics of the green bond sample before the matching process. The sample includes 1248 green bonds. The variables are defined in Table 12

$M T G$ senior secured and mortgage backed, SEC secured, $S R$ senior unsecured, $S R B N$ senior non-preferred, $S R P$ senior preferred, SRSEC senior secured, $U N$ unsecured

${ }^{a}$ Seniority indicates the combined information on bond seniority and collateral status on Eikon

${ }^{\mathrm{b}} \mathrm{NR}$ means that the green bond does not have a S\&P equivalent crediting rating on Eikon 


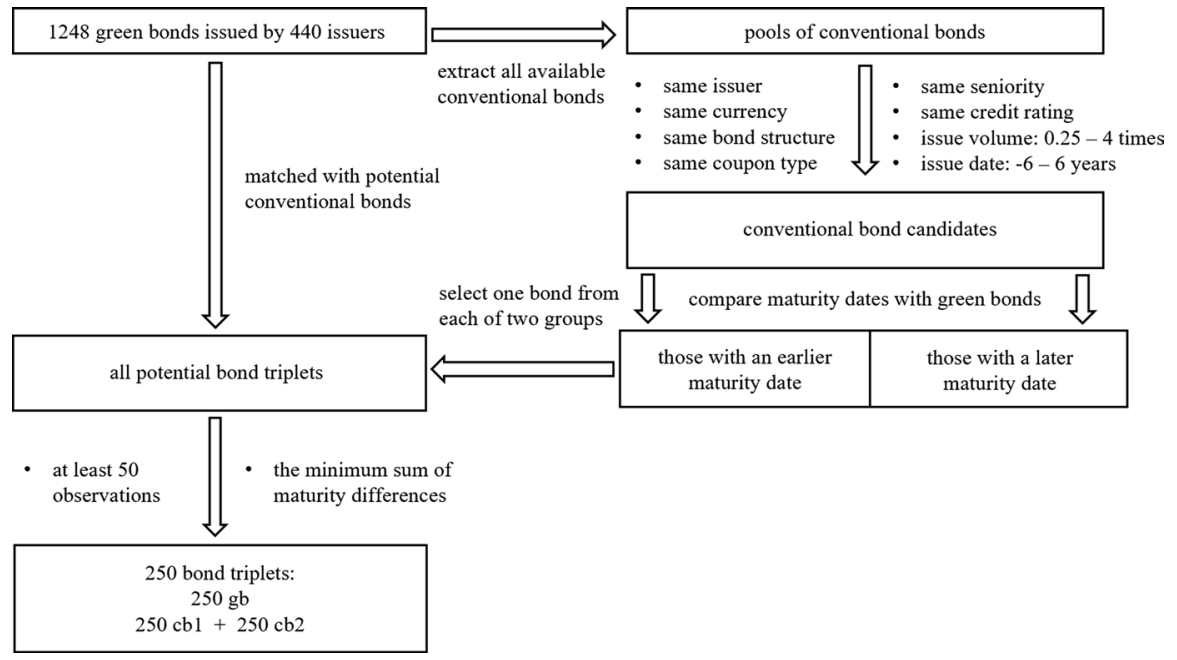

Fig. 2 The matching process

Funding Open Access funding enabled and organized by Projekt DEAL.

Open Access This article is licensed under a Creative Commons Attribution 4.0 International License, which permits use, sharing, adaptation, distribution and reproduction in any medium or format, as long as you give appropriate credit to the original author(s) and the source, provide a link to the Creative Commons licence, and indicate if changes were made. The images or other third party material in this article are included in the article's Creative Commons licence, unless indicated otherwise in a credit line to the material. If material is not included in the article's Creative Commons licence and your intended use is not permitted by statutory regulation or exceeds the permitted use, you will need to obtain permission directly from the copyright holder. To view a copy of this licence, visit http://creativecommons.org/licen ses/by/4.0/.

\section{References}

Amihud Y, Mendelson H (1986) Asset pricing and the bid-ask spread. J Financ Econ 17(2):223-249

Bachelet MJ, Becchetti L, Manfredonia S (2019) The green bonds premium puzzle: the role of issuer characteristics and third-party verification. Sustainability 11(4):1098

Baker M, Bergstresser D, Serafeim G, Wurgler J (2019) Financing the response to climate change: the pricing and ownership of U.S. green bonds. NBER working paper

Bell A, Jones K (2015) Explaining fixed effects: random effects modeling of time-series cross-sectional and panel data. Political Sci Res Methods 3(1):133-153

Berry R, Yeung F (2013) Are investors willing to sacrifice cash for morality? J Bus Ethics 117:477-492

Bolton P, Kacperczyk M (2021) Do investors care about carbon risk? J Financ Econ

Chava S (2014) Environmental externalities and cost of capital. Manag Sci 60(9):2111-2380

Cheema-Fox A, LaPerla BR, Serafeim G, Turkington D, Wang H (2019) Decarbonization Factors. SSRN Working Paper

Chen L, Lesmond DA, Wei J (2007) Corporate yield spreads and bond liquidity. J Financ 62(1):119-149

CICERO (2015) KfW green bond second opinion 2015. Technical report, CICERO

CICERO (2019) KfW green bond second opinion 2019. Technical report, CICERO

Climate Bond Initiative (2019a) Green bond European investor survey 2019. Technical report, Climate Change Initiative 
Climate Bond Initiative (2019b) Green bonds pricing in the primary market: January-June 2019. Technical report, Climate Change Initiative

Climate Bond Initiative (2020) 2019 green bond market summary. Technical report, Climate Change Initiative

Dhaliwal D, Radhakrishnan S, Tsang A, Yang YG (2012) Nonfinancial disclosure and analyst forecast accuracy: international evidence on corporate social responsibility disclosure. Account Rev 87(3):723-759

Dorfleitner G, Utz S (2012) Safety first portfolio choice based on financial and sustainability returns. Eur J Oper Res 221(1):155-164

Dorfleitner G, Utz S (2014) Profiling German-speaking socially responsible investors. Qual Res Financ Mark 6(2):118-156

Ehlers T, Packer F (2017) Green bond finance and certification. BIS Q Rev

Fama EF, French KR (2007) Disagreement, tastes, and asset prices. J Financ Econ 83(3):667-689

Fenn GW (2000) Speed of issuance and the adequacy of disclosure in the 144a high-yield debt market. J Financ Econ 56(3):383-405

Flammer C (2020) Corporate green bonds. J Financ Econ (forthcoming)

Ghoul SE, Guedhami O, Kwok CC, Mishra DR (2011) Does corporate social responsibility affect the cost of capital? J Bank Financ 35(9):2388-2406

Gutsche G, Ziegler A (2019) Which private investors are willing to pay for sustainable investments? Empirical evidence from stated choice experiments. J Bank Financ 102:193-214

Gutsche G, Zwergel B (2020) Investment barriers and labeling schemes for socially responsible investments. Schmalenbach Bus Rev 72:1-47

Gutsche G, Köbrich León A, Ziegler A (2019) On the relevance of contextual factors for socially responsible investments: an econometric analysis. Oxf Econ Pap 71(3):756-776

Hachenberg B, Schiereck D (2018) Are green bonds priced differently from conventional bonds? J Asset Manag 19(6):371-383

Hahn R, Kühnen M (2013) Determinants of sustainability reporting: a review of results, trends, theory, and opportunities in an expanding field of research. J Clean Prod 59:5-21

Harvey CR, Liu Y, Zhu H (2016) ... and the cross-section of expected returns. Rev Financ Stud 29(1):5-68

Heinkel R, Kraus A, Zechner J (2001) The effect of green investment on corporate behavior. J Financ Quant Anal 36(4):431-449

Höchstädter AK, Scheck B (2015) What's in a name: an analysis of impact investing understandings by academics and practitioners. J Bus Ethics 132(2):449-475

Hong H, Kacperczyk M (2009) The price of sin: the effects of social norms on markets. J Financ Econ 93(1):15-36

Kapraun J, Scheins C (2019) (In)-credibly green: which bonds trade at a green bond premium? SSRN Working Paper

Krueger P, Sautner Z, Starks LT (2020) The importance of climate risks for institutional investors. Rev Financ Stud 33(3):1067-1111

Larcker DF, Watts EM (2020) Where's the greenium? J Account Econ 69:101312

Li Z, Tang Y, Wu J, Zhang J, Lv Q (2019) The interest costs of green bonds: credit ratings, corporate social responsibility, and certification. Emerg Mark Financ Trade 56:2679-2692

Mundlak Y (1978) On the pooling of time series and cross section data. Econometrica 46(1):69-85

Nanayakkara M, Colombage S (2019) Do investors in green bond market pay a premium? Global evidence. Appl Econ 51(40):4425-4437

Nyilasy G, Gangadharbatla H, Paladino A (2014) Perceived greenwashing: the interactive effects of green advertising and corporate environmental performance on consumer reactions. J Bus Ethics 125(4):693-707

Orlitzky M, Schmidt FL, Rynes SL (2003) Corporate social and financial performance: a meta-analysis. Organ Stud 24(3):403-441

Painter M (2020) An inconvenient cost: the effects of climate change on municipal bonds. J Financ Econ 135(2):468-482

Riedl A, Smeets P (2017) Why do investors hold socially responsible mutual funds? J Financ 72(6):2505-2550

Schestag R, Schuster P, Uhrig-Homburg M (2016) Measuring liquidity in bond markets. Rev Financ Stud 29(5):1170-1219 
Schunck R (2013) Within and between estimates in random-effects models: advantages and drawbacks of correlated random effects and hybrid models. Stata J 13(1):65-76

Shishlov I, Morel R, Cochran I (2016) Beyond transparency: unlocking the full potential of green bonds. Institute for Climate Economics Report

Tang TT (2009) Information asymmetry and firms' credit market access: evidence from Moody's credit rating format refinement. J Financ Econ 93(2):325-351

Walker K, Wan F (2012) The harm of symbolic actions and green-washing: corporate actions and communications on environmental performance and their financial implications. J Bus Ethics 109(2):227-242

Wulandari F, Schäfer D, Stephan A, Suna C (2018) The impact of liquidity risk on the yield spread of green bonds. Financ Res Lett 27:53-59

Zerbib OD (2019) The effect of pro-environmental preferences on bond prices: evidence from green bonds. J Bank Financ 98:39-60

Publisher's Note Springer Nature remains neutral with regard to jurisdictional claims in published maps and institutional affiliations. 